LOS COSTOS ASOCIADOS AL PROCESO DESINFLACIONARIO

O scar Sánchez, Juan Seade y Alejandro Werner

Mayo de 1999

Documento de Investigación No. 9903

Dirección General de Investigación Económica

BANCO DE MÉXICO 


\title{
LOS COSTOS ASOCIADOS AL PROCESO DESINFLACIONARIO
}

\author{
O scar Sánchez, Juan Seade y Alejandro Werner* \\ BANCO DE MÉXICO \\ Mayo de 1999 \\ Documento de Investigación No. 9903
}

\section{RE SUMEN}

En este trabajo se lleva a cabo un estudio de las regularidades empíricas de los procesos desinflacionarios implementados en distintos países durante el período 1970-1998. Para revertir las tendencias inflacionarias la autoridad monetaria debe implementar políticas monetarias restrictivas, estas políticas elevan la tasa de interés real y aprecian el tipo de cambio real, lo que afecta la tasa de crecimiento de la economía. El análisis de este trabajo se enfoca en identificar los determinantes de los costos asociados a la reducción en la tasa de inflación. Se presenta además un modelo macroeconomico que intenta capturar los elementos relevantes del proceso desinflacionario y de los costos asociados al mismo.

\footnotetext{
* Los autores agradecen los comentarios de Agustín Carstens, Lorenza Martínez y Moisés Schwartz. Las opiniones contenidas en este documento corresponden exclusivamente a los autores y no representan el punto de vista del Banco de México.
} 


\section{Contenido}

Introducción. .5

I. Comparación internacional de los costos asociados al proceso desinflacionario................8

I.1 Estimación del coeficiente de sacrificio.............................................................

Identificación de episodios de desinflación................................................8

Cálculo de las pérdidas en producción asociadas a la desinflación............11

Principales características de los episodios desinflacionarios.....................14

I.2 El coeficiente de sacrificio y su relación con la velocidad

de desinflación, la inflación inicial, la duración del

periodo desinflacionario y la reducción en la inflación

Velocidad de desinflación.........................................................................17

Inflación inicial......................................................................................18

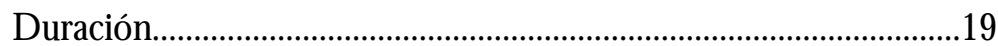

I.3 La desinflación y el régimen cambiario .................................................................23

El coeficiente de sacrificio y el régimen cambiario....................................24

La velocidad de desinflación y el régimen cambiario................................27

II $\quad$ Modelo de desinflación y de los determinantes de su costo.............................................28

Un modelo de desinflación y de los

determinantes del coeficiente de sacrificio

La solución del modelo.............................................................................33

Ejercicios de simulación...........................................................................35

La inercia salarial y el coeficiente de sacrificio........................................40

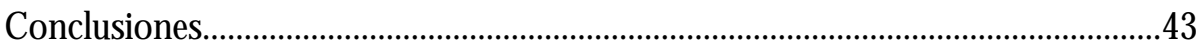

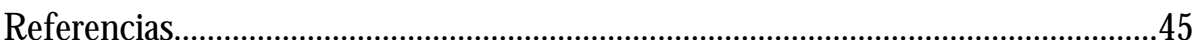

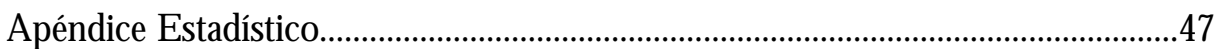




\section{Lista de $\mathrm{G}$ ráficas}

Gráfica 1: Tendencia inflacionaria de Alemania, Canadá y Holanda.....................................

Gráfica 2: $\quad$ PIB durante las desinflaciones de Alemania, Canadá y Holanda......................... 13

Gráfica 3: $\quad$ Velocidad de desinflación vs. Razón de sacrificio ..................................................18

Gráfica 4: $\quad$ Inflación inicial vs. Razón de sacrificio ................................................................. 19

Gráfica 5: $\quad$ D uración vs. Razón de sacrificio ...........................................................................20

Gráfica 6: $\quad$ Inflación inicial vs. Razón de sacrificio con distintos

regímenes cambiarios (toda la muestra) ...........................................................24

Gráfica 7: Inflación inicial vs. Razón de sacrificio con distintos

regímenes cambiarios (desinflaciones sostenibles)................................................26

Gráfica 8: $\quad$ Inflación inicial vs. Velocidad de desinflación

con distintos regímenes cambiarios..................................................................28

Gráfica 9: $\quad$ Evolución de las variables

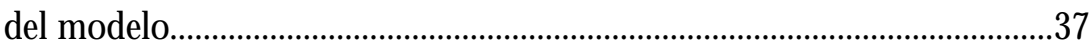

\section{Lista de Cuadros}

Cuadro 1: $\quad$ Estadísticas selectas de las desinflaciones...............................................................16

Cuadro 2: $\quad$ Resultados de las regresiones.............................................................................21

Cuadro 3: $\quad$ Evolución de las variables en el modelo...............................................................39

Cuadro 4: $\quad$ Evolución de las variables en el modelo................................................................

\section{Lista de D iagramas}

Diagrama 1: Canales de transimisión de la política monetaria...............................................31 


\section{LOS COSTOS ASOCIADOS AL PROCESO DESINFLACIONARIO}

\section{Introducción}

En este trabajo se lleva a cabo un estudio de las regularidades empíricas de los procesos desinflacionarios implementados en distintos países durante el período 1970-1998. El análisis se enfoca en identificar los determinantes de los costos asociados a la reducción en la tasa de inflación. Se presenta además un modelo teórico que intenta capturar los elementos relevantes del proceso desinflacionario y de los costos asociados al mismo.

La autoridad monetaria debe implementar políticas monetarias restrictivas con el objeto de reducir la tasa de crecimiento de los precios y revertir la tendencia de las expectativas inflacionarias. Estas políticas elevan la tasa de interés real y aprecian el tipo de cambio real, lo que afecta la tasa de crecimiento de la economía.

El costo asociado a los procesos desinflacionarios varía considerablemente entre los distintos episodios. Los elementos que se señalan en la literatura como determinantes de los costos de un programa desinflacionario son ${ }^{1}$ :

1. La frecuencia de las negociaciones laborales. D ado que el cambio de política monetaria no siempre ocurre al unísono de la negociación salarial, existen contratos ya pactados bajo expectativas de permanencia de la inflación. En este contexto, mientras menos frecuente sea la renegociación de los contratos, más difícil será reducir la inflación salarial, lo que contribuirá a aumentar el costo asociado a la desinflación.

2. La credibilidad de la autoridad monetaria. A menos de que el compromiso desinflacionario por parte del banco central sea creíble, las expectativas de inflación se ajustarán lentamente. Esto provoca que las negociaciones salariales se realicen con base en una inflación esperada mayor al objetivo, contribuyendo a aumentar los costos asociados a la desinflación. Es importante considerar además que el concepto de credibilidad implica que ambas políticas, fiscal y monetaria, deben ser coherentes con el objetivo de menor inflación.

\footnotetext{
${ }^{1}$ Véase Blanchard (1998).
} 
3. La sensibilidad a la baja del salario real. Puesto que en la práctica ni los contratos laborales se revisan continuamente, ni la política de desinflación es perfectamente creíble, el éxito de ésta depende de la capacidad de las autoridades para forzar una caída en el salario real, generando presiones recesivas que limiten los aumentos en los salarios contractuales. Esto es, dada la expectativa actual de inflación, un menor incremento de los salarios nominales es la única manera de generar el círculo virtuoso de la desinflación. Por lo tanto, mientras más sensible sea el salario real a las condiciones de demanda agregada menor será el costo asociado a la desinflación.

4. La capacidad para apreciar el tipo de cambio real. En una economía abierta la apreciación del tipo de cambio real es un factor adicional capaz de contribuir a generar ganancias en el proceso de desinflación. Sin embargo, estas ganancias podrían resultar efímeras si la apreciación real genera un desequilibrio insostenible en las cuentas externas.

Los costos incurridos por los países al llevar a cabo políticas dirigidas a una reducción sustantiva de la tasa de inflación pueden ser cuantificados por medio del denominado Coeficiente de Sacrificio (CS). Este mide el costo en puntos del PIB de reducir la tasa de inflación en un punto porcentual.

Si bien existe un consenso con respecto a los factores que contribuyen a disminuir el costo de las políticas desinflacionarias, aún no se ha llegado a un consenso con respecto a la velocidad óptima de desinflación.

La proposición tradiaional señala a la frecuencia de las negociaciones laborales como el determinante primordial de los costos asociados a la desinflación (Fischer (1988) y Taylor (1983)). La hipótesis es que la existencia de contratos laborales preestablecidos impide evitar los costos de la desinflación, aun cuando las expectativas cambiasen inmediatamente. De modo que una desinflación gradual puede resultar menos costosa puesto que permite el tiempo suficiente para el ajuste de los salarios y precios a la nueva postura de política del banco central.

Una posición altemativa, desarrollada por Sargent (1983) en el contexto de las hiperinflaciones de los 1980s, propone que solo mediante un viraje drástico de política es posible alterar el mecanismo de formación de expectativas. De esta forma, un compromiso de desinflación rápida provoca ganancias de credibilidad claves en la reducción de los costos asociados a la desinflación. 
Finalmente, algunos economistas sugieren que la desinflación será menos costosa siempre que vaya acompañada de políticas de ingreso, o por esfuerzos adicionales que contribuyan a coordinar el ajuste en precios y salarios. Además existen características del ambiente económico que afectan al trueque entre inflación y producto, como son el nivel de la inflación inicial (Ball, Mankiw, Romer 1988) y el grado de apertura de la economía (Romer 1991).

El convencimiento público de los costos generados por la inflación ha sido tal que en los últimos años, en muchas naciones, se ha dotado de autonomía a los bancos centrales, acotando el campo de acción de la política monetaria a la procuración de la estabilidad de precios. El resultado no se ha hecho esperar. La inflación promedio de los países industrializados descendió a 5\% a mediados de los ochenta, y a $2 \%$ en la actualidad. Este fenómeno refleja claramente la voluntad a nivel mundial de incurrir, en el corto plazo, en los costos asociados a los procesos desinflacionarios para obtener los beneficios de largo plazo que la estabilidad de precios trae consigo.

En la primera parte del trabajo se presenta una metodología para la estimación del coeficiente de sacrificio. A continuación analizamos los episodios desinflacionarios de una muestra de 24 países a lo largo del período 1970-1998. Con base en esta muestra, estudiamos la relación entre el coeficiente de sacrificio, la velocidad de desinflación, la inflación inicial, y el nivel del tipo de cambio real. Encontramos que el coeficiente de sacrificio es, por lo general, positivo, lo cual indica que en la mayoría de los casos los procesos desinflacionarios han tenido costos en términos del producto. En segundo lugar se observa que dichos costos han estado inversamente relacionados con la inflación inicial. Observamos además que el tipo de cambio real se aprecia, en promedio, durante las desinflaciones. Es por esto, y dado que la demanda agregada depende inversamente de la tasa de interés real, y directamente del tipo de cambio real, que las desinflaciones implican una reducción en el ritmo de crecimiento de la economía. A partir de la evidencia empírica concluimos que las desinflaciones, en promedio, implican costos, y que son generadas por políticas monetarias restrictivas, que en una economía abierta aprecian el tipo de cambio real.

En la segunda parte del trabajo presentamos un modelo macroeconómico que intenta capturar las regularidades empíricas observadas anteriormente. En este modelo consideramos como distintas posturas de política monetaria por parte del banco central determinan tanto el costo asociado a la desinflación como la velocidad de convergencia al objetivo de largo plazo de la autoridad monetaria. A partir de la calibración del modelo, realizamos una serie de ejercicios de simulación, concentrándonos en la transición de un nivel moderado a una inflación de un dígito. Encontramos que una postura de política monetaria más restrictiva provoca una alza en el costo de la desinflación. De modo que en el 
modelo que aquí se presenta existe una relación directa entre la velocidad de desinflación y la razón de sacrificio. Sin embargo, elaborando sobre el proceso de formación de expectativas de los asalariados, encontramos que a medida que estas expectativas se parecen más a las determinadas por el mismo modelo (son más racionales), se reduce la velocidad de convergencia de la inflación salarial al objetivo, lo que aminora los costos de la desinflación. Además, en la medida en la que una postura desinflacionaria más estricta aumenta la credibilidad del compromiso de la autoridad monetaria con la desinflación, se reducirá el costo asociado a la misma. Por lo tanto, una vez que se analizan todos los efectos, el impacto de una política monetaria más restrictiva sobre la razón de sacrificio es ambiguo. Finalmente, presentamos las conclusiones principales del estudio.

\section{Comparación Intemacional de los Costos Asociados al Proceso Desinflacionario}

\section{I.1 Estimación del Coeficiente de Sacrificio}

\section{Identificación dequisodios dedesinflación}

En primer lugar, nos interesa caracterizar a aquellos períodos en los que la tasa de inflación experimenta una caída sustancial. Partiendo del criterio utilizado por Ball (1994) se denomina episodio de desinflación a aquel período en donde la tendencia de la tasa de inflación presenta una caída sustancial. En este estudio la tendenia de la inflación se calcula como la media móvil 


\section{Gráfica 1}

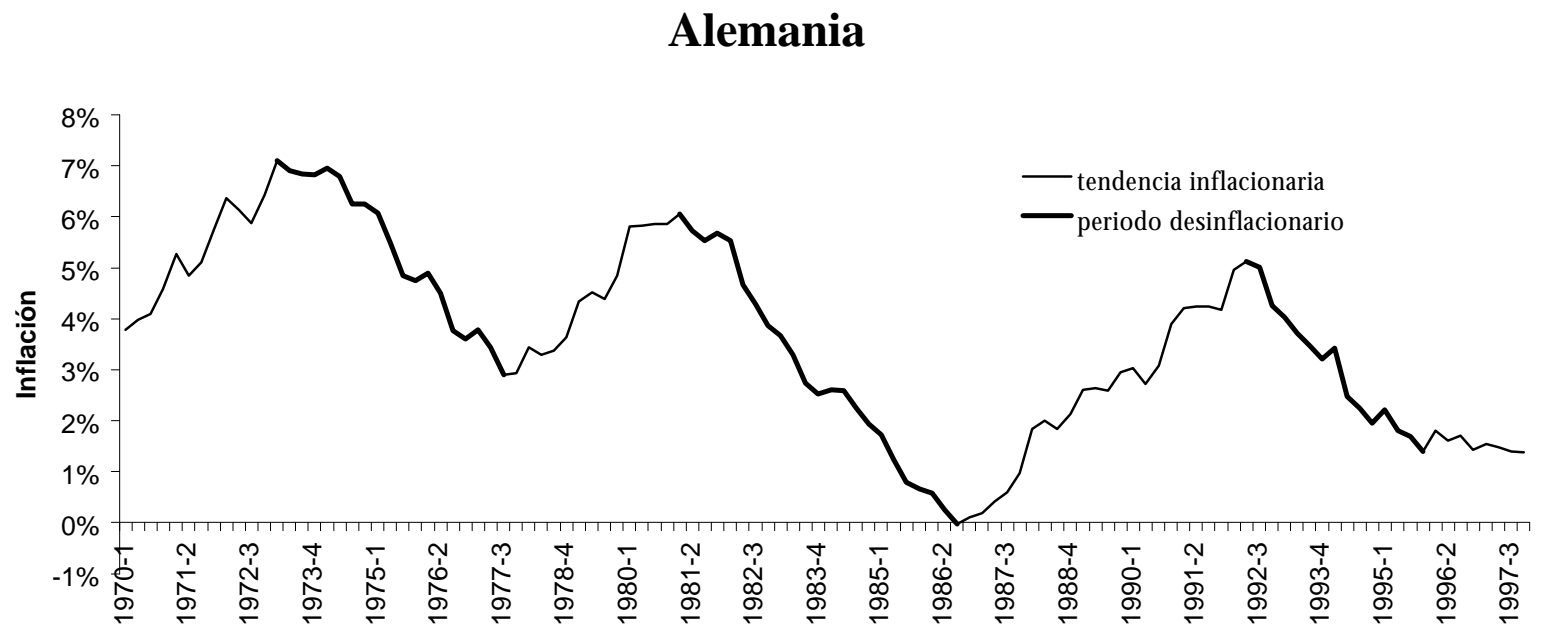

\section{Canadá}

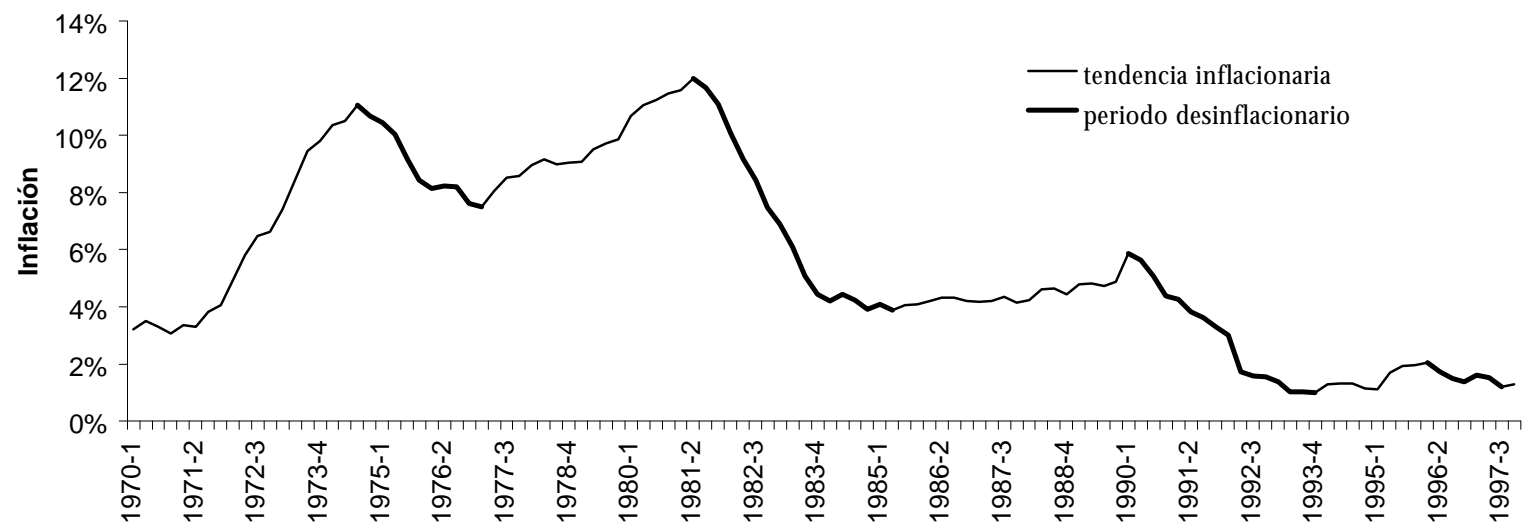

\section{Holanda}

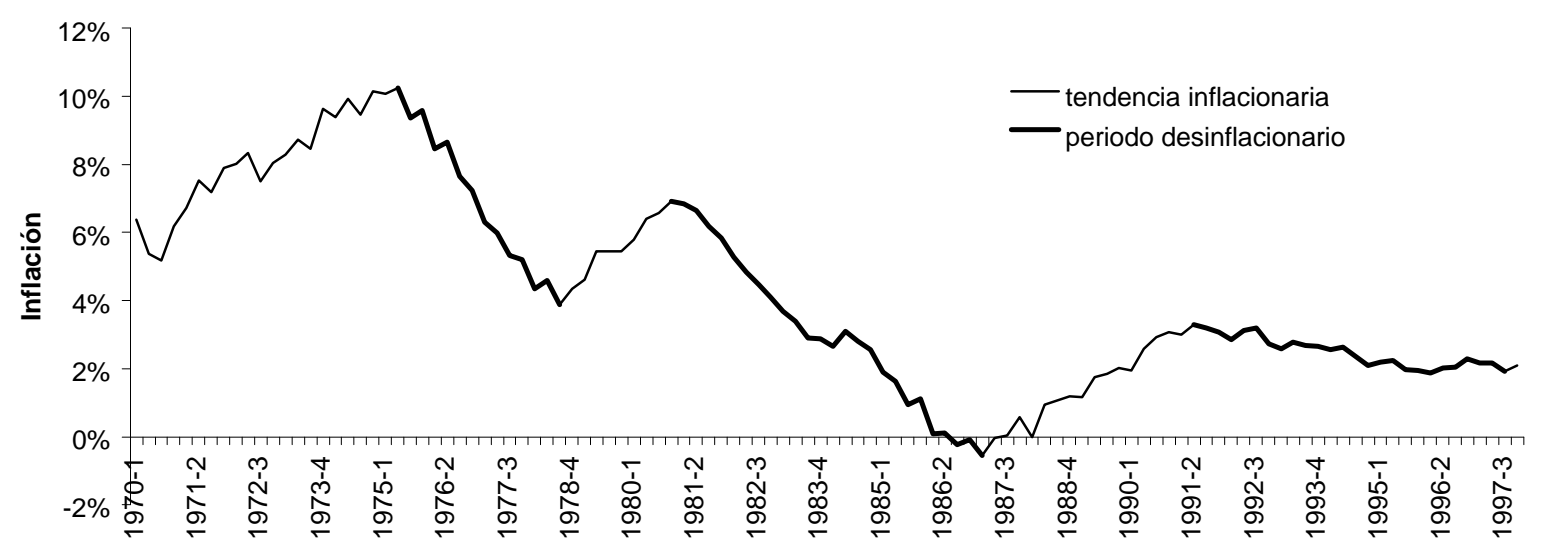


centrada de nueve trimestres de la inflación trimestral anualizada. Con el fin de evitar considerar las fluctuaciones aleatorias o estacionales en la tasa de inflación, se consideran aquí episodios de desinflación solo a aquellos períodos en los que la caída en la tendencia de la inflación anualizada es mayor al 2\%. Finalmente, la duración del episodio de desinflación es el número de trimestres transcurridos entre el "pico" y el "valle" de la tendencia inflacionaria.

D e acuerdo a la metodología anterior, cada episodio desinflacionario queda caracterizado por:

- inflación inicial $\pi_{0}$,

- inflación final $\pi_{T}$,

- duración T,

- velocidad de desinflación $v_{\pi}$ (la reducción en inflación por unidad de tiempo considerada- por trimestre en este estudio).

Los datos que se utilizaron en la estimación provienen de las Estadísticas Financieras Internacionales (EFI) del Fondo Monetario Internacional (FMI). Los países que se incluyeron en el estudio son: Alemania, Argentina, Australia, Austria, Canadá, Chile, Corea, D inamarca, Ecuador, España, Estados Unidos, Filipinas, Finlandia, Holanda, Israel, Italia, Japón, México, Noruega, Nueva Zelandia, Portugal, Reino Unido, Suecia y Suiza. Finalmente, el estudio se hizo para el periodo 1970-1998.

En la Gráfica 1 se aprecia como de acuerdo a la metodología descrita se identifican los episodios desinflacionarios para una muestra de tres países. El procedimiento intenta separar cambios significativos en la inflación inducidos por la política monetaria de las fluctuaciones provocadas por las perturbaciones de otra naturaleza. Esto parece haberse conseguido, ya que los episodios identificados coinciden con los momentos en los que se aplicó una política monetaria restrictiva en los países considerados.

Para obtener el coeficiente de sacrificio asociado a un episodio desinflacionario, solamente queda por medir la pérdida observada en puntos del PIB. En el siguiente apartado se describe la metodología utilizada para calcular estas pérdidas.

\section{Cálailodelas pédidas en producción asciadas a la dkinflaaión}


El coeficiente de sacrificio se construye calculando el cociente entre la suma de las pérdidas logarítmicas en el PIB y el descenso en la tasa de inflación. Las pérdidas logarítmicas en el PIB observadas durante la desinflación se calculan como la desviación con respecto al nivel logarítmico del PIB potencial. De esta forma, el numerador del coeficiente de sacrificio es la pérdida porcentual en el producto trimestral acumulada a lo largo del episodio, y el denominador es la reducción observada en la inflación. La cantidad resultante se interpreta como el costo, en puntos del PIB, de reducir la tasa de inflación en un punto porcentual.

El nivel potencial de producción o de "pleno empleo" es el nivel que supuestamente se hubiese alcanzado en ausencia del esfuerzo desinflacionario. Uno de los problemas más delicados en el cálculo del coeficiente de sacrificio es precisamente la medición de estas pérdidas en producción, ya que su estimación variará sensiblemente dependiendo de la metodología utilizada para medir el nivel del producto potencial.

Las formas tradicionales de llevar a cabo esta tarea son por medio de tendencias lineales cambiantes en el tiempo o por medio de ajustes no lineales como el filtro de Hodrick y Prescott². Sin embargo, la minimización de las diferencias entre la tendencia y el producto observado que caracteriza a estos métodos, reduce o elimina la presencia de las recesiones que nos interesa capturar.

Para calcular las pérdidas asociadas a un episodio desinflacionario se echa mano en este estudio del criterio utilizado por Ball (1994). Los supuestos de la metodología de Ball son los siguientes:

i) El PIB se encuentra en su nivel potencial al principio del episodio desinflacionario.

ii) El PIB regresa a su nivel potencial cuatro trimestres después de concluído el episodio desinflacionario.

iii) Finalmente, se asume que el logaritmo del PIB potencial crece linealmente entre el logaritmo del PIB observado al principio y el final del episodio desinflacionario.

${ }^{2}$ Véase Hodrick y Prescott (1997) 
De modo que esta metodología supone que el PIB potencial crece a una tasa constante durante el episodio desinflacionario, de forma tal que el costo de la desinflación se mide como las desviaciones acumuladas entre el PIB observado y esta tendencia logarítmica3.

Para el presente trabajo se aplicó el método anterior utilizando el PIB observado a precios de 1990 con frecuencia trimestral. Puesto que los datos obtenidos del PIB real no están desestacionalizados, se empleó aquí la media móvil de cuatro trimestres de la serie estacional.

En la Gráfica 2 se ilustran las pérdidas en producción durante algunos episodios de desinflación señalados anteriormente para Alemania, Holanda, y Canadá. El coeficiente de sacrificio no es más que el área entre la línea punteada y la línea continua, dividida por el número de puntos porcentuales de desinflación. Como se puede observar en la gráfica, por ejemplo para el caso de Alemania, el PIB observado resulta menor al potencial durante el período que va de 1981:3 a 1986:3. Este período coincide con uno de los episodios de desinflación identificados para Alemania en la gráfica 1. De modo que durante la desinflación, cuando el banco central implementa una política monetaria restrictiva que eleva la tasa de interés, la economía se mueve a lo largo de la curva de Phillips reduciendo la inflación y aumentando la brecha del PIB con respecto al PIB potencial. Dado que en largo plazo las expectativas de inflación se ajustarán al nuevo nivel de la inflación observada, la brecha del PIB se cierra volviendo el nivel observado a coincidir con el PIB potencial. No es difícil ver que lo anterior se cumple para el resto de las desinflaciones ilustradas en la gráfica 1.

\footnotetext{
${ }^{3}$ Este último supuesto concuerda con los modelos teóricos de crecimiento económico donde el PIB crece a una tasa constante.
} 


\section{Gráfica 2}

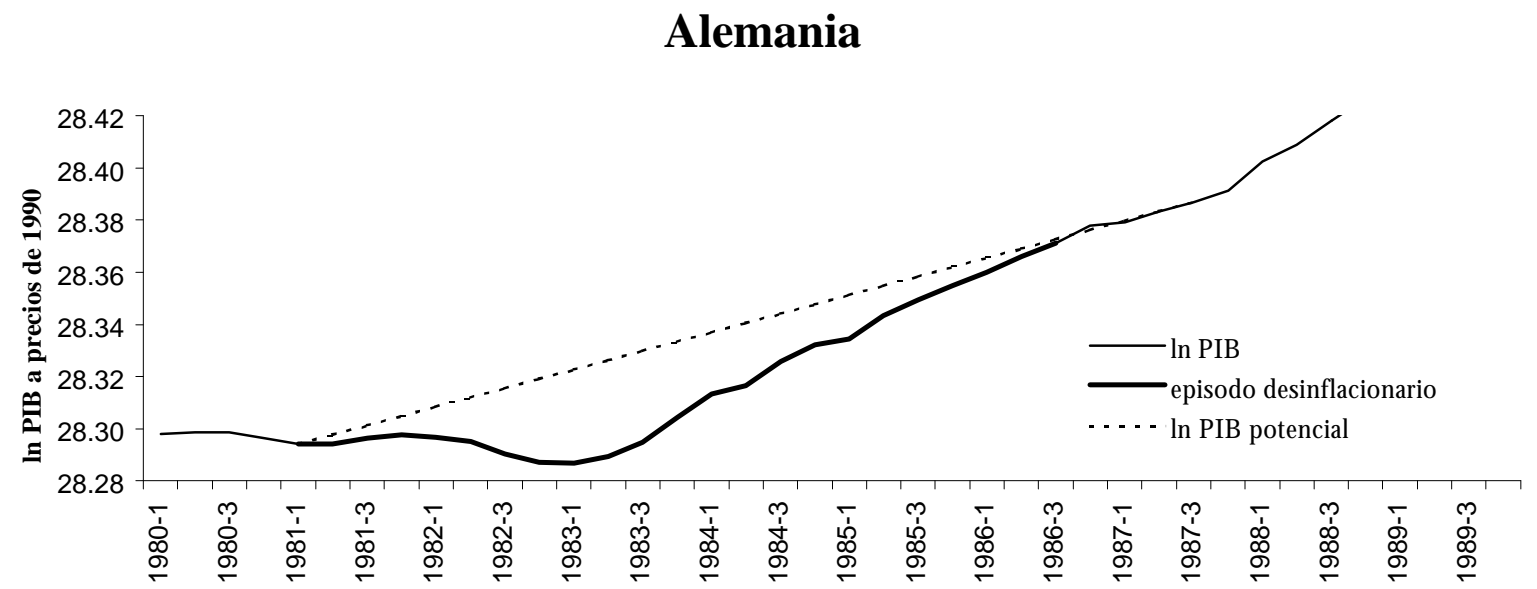

Canadá

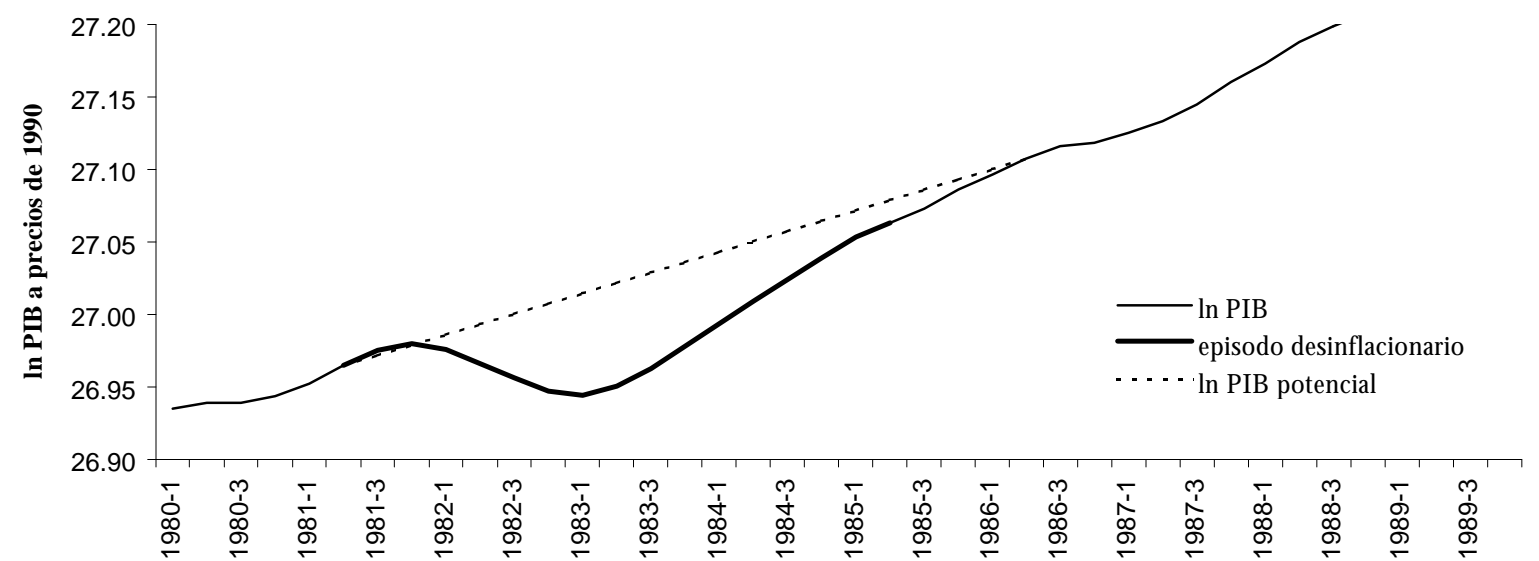

Holanda

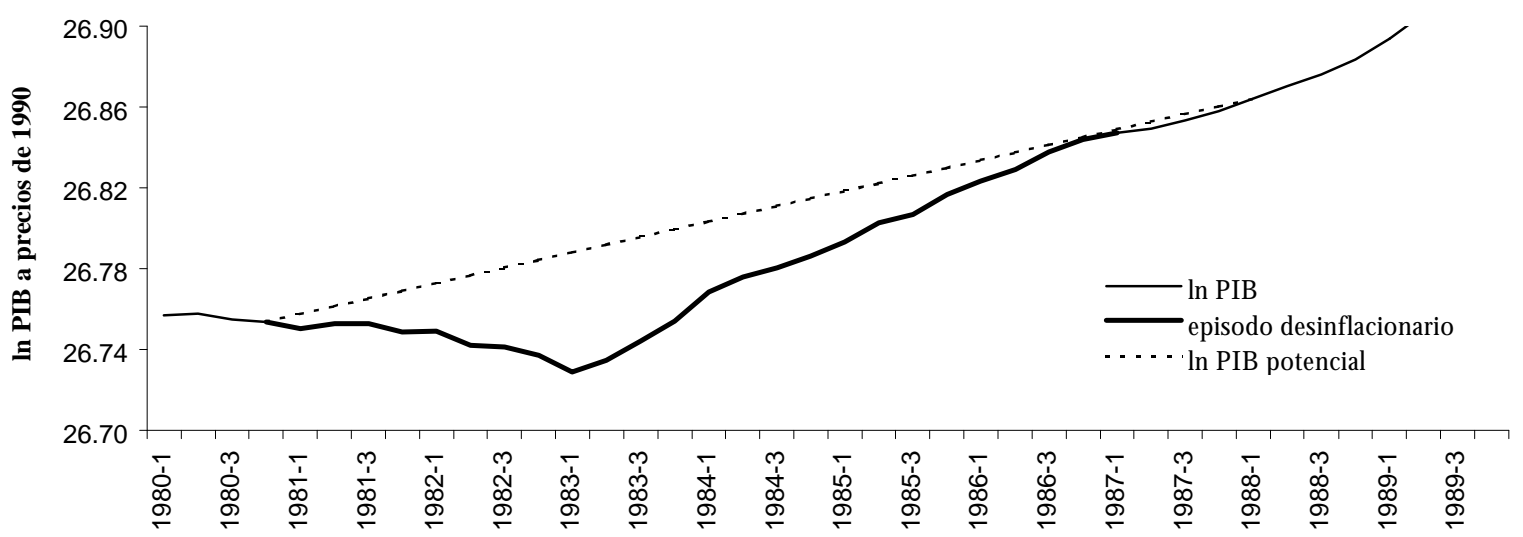




\section{Prinapales caracteísticas delos episodios desinflacionarios}

A continuación se enumeran los resultados principales de este ejercicio:

Para analizar los resultados dividimos la muestra de acuerdo al nivel de la inflación inicial. Los resultados se presentan en los cuadros A-1 a A-5 del apéndice estadístico.

Notamos, en primer lugar, que existen episodios para los cuales la razón de sacrificio resulta negativa, lo cual implicaría que la desinflación no implicó un costo. Esto es, que la desinflación no está asociada a una disminución en el ritmo de crecimiento de la economía. Sin embargo, como se analiza a continuación, al examinar con más cuidado estos episodios encontramos que para la mayoría de ellos la desinflación pudo muy bien no haber sido una política sostenible en el largo plazo.

Por ejemplo, entre los episodios que partieron de un nivel de inflación mayor al 40\% (cuadro A-5) está el caso de Argentina (1976:2-1980:4) donde la inflación observada en promedio durante los dos años posteriores al episodio desinflacionario resulta considerablemente mayor a su inflación inicial. Lo mismo sucede para los episodios Israel (1974:1-1976:2), e Israel (1980:4-1982:1). Bajo el mismo criterio cae el episodio de Noruega (1975:1-1978:4), que parte de una inflación inicial de 10.8\% (cuadro A-3). Finalmente, en el episodio Japón (1974:1-1978:3) se observa que aunque la inflación inicial es mayor a la inflación posterior al episodio, esta última se revierte a un nivel moderado. De modo que no es posible calificar a la desinflación como sostenible en el largo plazo.

Por otro lado, entre los episodios que parten de un nivel de inflación mayor al 40\% (cuadro A-5) observamos que existen episodios para los que la razón de sacrificio no resulta menor a cero, más sí muy cercana a cero. Este es el caso de los dos episodios: Argentina (1984:3-1986:3), México (1983:21984:3) y México (1987:1-1993:4). Para los primeros dos episodios, al igual que en los episodios de Argentina e Israel comentados más arriba, la inflación posterior al episodio sobrepasa a la inflación inicial. Acerca del tercer episodio se observa que aunque la inflación inicial es mayor a la inflación posterior al episodio, esta última se revierte a un nivel moderado al terminar el episodio. Por lo tanto, la política de desinflación no se puede calificar como sostenible en el largo plazo.

Concluimos entonces, que de los 12 episodios desinflacionarios para los cuales la razón de sacrificio resulta negativa, 5 resultan no sostenibles en el largo plazo. De modo que quedan 7 episodios por explicar, los cuales son: Japón (1990:2-1996:1), Italia (1995:1-1996:3), Israel (1989:4-1993:1), Suecia (1993:4-1997:3), y Australia (1986:2-1993:1). De estos Japón (1990:2-1996:1) sobresale por la 
apreciación real, y la inflación de activos, observada durante el episodio, la cual condujo a una depresión en el crecimiento vigente a la fecha, por lo que solamente se pospuso la recesión. Por otro lado, el episodio de Italia (1995:1-1996:3) se encuentra asociado al cumplimiento de los criterios de Maastrich para la calificación a la primera ronda del Euro, por lo que el efecto de la credibilidad de la política de desinflación resulta significativo en este caso. Por lo tanto, solamente quedan los casos de ${ }^{4}$ A ustralia, Israel, y Suecia.

En resumen, para la mayoría de los episodios que resultan con razones de sacrificio negativas encontramos que la política de desinflación no fue sostenible en el mediano plazo, o estuvo asociada a efectos favorables de credibilidad que provocaron una reducción significativa en los costos de la desinflación.

Finalmente, existen episodios para los cuales no fue posible calcular la razón de sacrificio por no disponer de datos de PIB trimestral para el período de la desinflación. Estos son los episodios: Ecuador (1977:3-1978:4), Estados Unidos (1974:2-1976:4), Nueva Zelandia (1976:2-1978:1), Nueva Zelandia (1980:2-1983:4), y México (1974:2-1975:3).

Con el objeto de presentar los resultados de forma compacta en el cuadro 1 incluimos, para cada rango de inflación inicial, únicamente los promedios tanto de la velocidad de desinflación como de la razón de sacrificio, y la depreciación del tipo de cambio real, para aquellos episodios para los que se obtienen razones de sacrificio positivas.

\footnotetext{
${ }^{4}$ El análisis que se presenta a continuación se llevó a cabo con base en una muestra que no incluye los episodios con razones de sacrificio negativas. Sin embargo, también se llevó a cabo este análisis para una muestra que incluye aquellos casos de desinflaciones sostenibles con razones de sacrificio negativas. Finalmente, el análisis se llevó a cabo para toda la muestra. Las diferencias en los resultados no fueron significativas.
} 


\section{Cuadro 1}

\begin{tabular}{|c||c|c|c|c|}
\hline \hline & \multicolumn{3}{|c|}{ Inflación inicial $^{\star}$} \\
\cline { 2 - 5 } & Mayor a 40\% & Entre 20 y 40\% & Entre 10 y 20\% & Menor a 10\% \\
\hline \hline Velocidad de Desinflación Promedio & 35.45 & 1.91 & 0.50 & 0.26 \\
\hline \hline Coeficiente de Sacrificio Promedio & 0.01 & 0.65 & 1.65 & 2.42 \\
\hline \hline $\begin{array}{c}\text { Depreciación Real } \\
\text { Promedio Desinflación }\end{array}$ & -14.58 & -2.22 & -5.22 & 1.61 \\
\hline \hline
\end{tabular}

* Se toman en cuenta únicamente aquellas desinflaciones para las que el coeficiente de sacrificio resultan positivas. Se descartan aquellas desinflaciones que no fueron sostenibles, conforme a los criterios ilustrados anteriormente.

Con base en los resultados del cuadro 1 observamos que la razón de sacrificio aumenta a medida que disminuye la inflación inicial, y la velocidad de desinflación aumenta a medida que aumenta la inflación inicial. Finalmente, observamos que durante la desinflación el tipo de cambio real se aprecia en la mayoría de los casos, y esta apreciación es mayor cuando la inflación inicial es más alta.

A continuación examinamos con más detalle la relación entre el coeficiente de sacrificio y las variables que caracterizan a los episodios de desinflación.

\section{I.2 El coeficiente de sacrificio y su relación con la velocidad de desinflación, la inflación inicial, la duración del periodo desinflacionario y la reducción en la inflación}

En esta sección analizamos la relación entre el coeficiente de sacrificio, asociado a los episodios identificados anteriormente, y la velocidad de desinflación, la inflación inicial, la duración del episodio, y la reducción en la inflación. Únicamente tomamos en cuenta los episodios desinflacionarios que se asocian con un coeficiente de sacrificio positivo ${ }^{5}$.

Como mencionábamos en la introducción a este trabajo, algunos economistas mantienen que el costo total en que incurren los países que aplican políticas monetarias restrictivas para disminuir la inflación es menor cuando el episodio de desinflación es largo, ya que los precios y salarios tienen tiempo de ajustarse. Sin embargo, otros economistas, como Sargent (1983), argumentan que si el episodio

\footnotetext{
${ }^{5}$ Nótese que automáticamente se descarta además aquellos episodios para los que no fue posible contabilizar la razón de sacrificio.
} 
desinflacionario es corto, es muy probable que sea menos costoso ya que las expectativas se ajustan rápidamente.

\section{V docidaddedesinflacoón}

En nuestra muestra encontramos una relación inversa no lineal entre las razones de sacrificio y la velocidad de desinflación. En la G ráfica 3 se puede apreciar el diagrama de dispersión para las razones de sacrificio positivas con sus respectivas velocidades de desinflación. La relación entre el coeficiente de sacrificio y la velocidad de desinflación es linealmente decreciente entre los logaritmos de estas variables, lo cual implica que la relación entre estas variables es decreciente a tasas decrecientes (como se puede observar en la gráfica 3). En otras palabras, mientras mayor sea la velocidad, un aumento de la misma magnitud en la velocidad de desinflación está asociada con un menor descenso en el coeficiente de sacrificio.

Como se verá en seguida, las demás variables analizadas también presentaron una relación lineal entre sus logaritmos y el logaritmo del coeficiente de sacrificio. 


\section{Gráfica 3}

\section{Velocidad de desinflación vs. Razón de sacrificio}

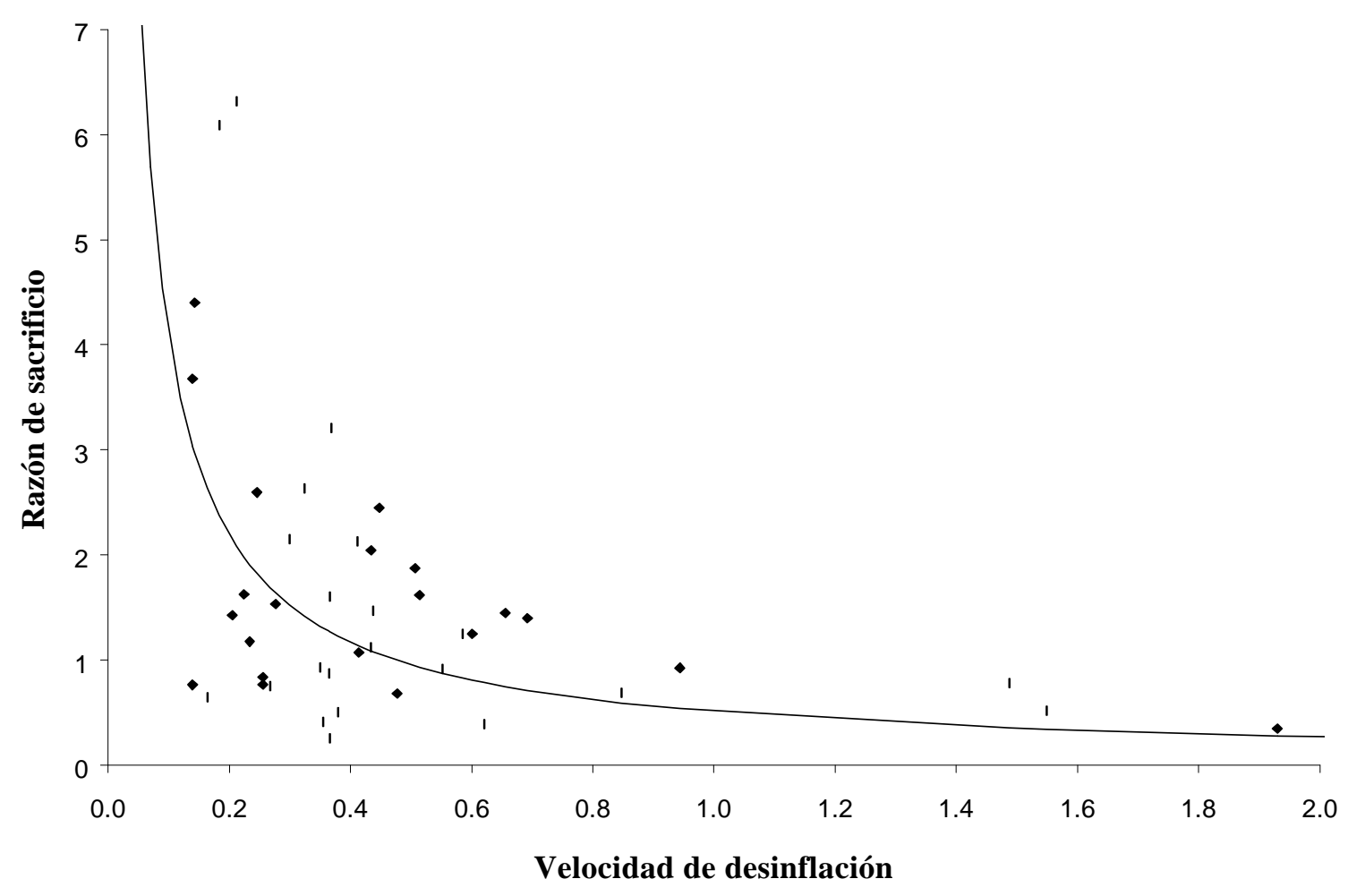

Inflacióninicial

En este apartado se relaciona la inflación al inicio de cada episodio desinflacionario con las razones de sacrificio. A este respecto existe el argumento de Ball, Mankiw y Romer (1988), según el cual una mayor inflación inicial generará un menor grado de rigidez nominal, reduciendo la pendiente de la curva de Phillips y reduciendo los costos del proceso de reducción de la inflación.

Como se puede observar en el Cuadro 2, se encontró que existe una relación inversa entre la inflación al inicio del periodo desinflacionario y el coeficiente de sacrificio, por lo que se puede decir que mientras más baja sea la inflación inicial es más costoso disminuirla. En la Gráfica 4 se aprecia esta relación inversa entre la inflación inicial y el coeficiente de sacrificio. 


\section{Gráfica 4}

\section{Inflación inicial vs. Razón de sacrificio}

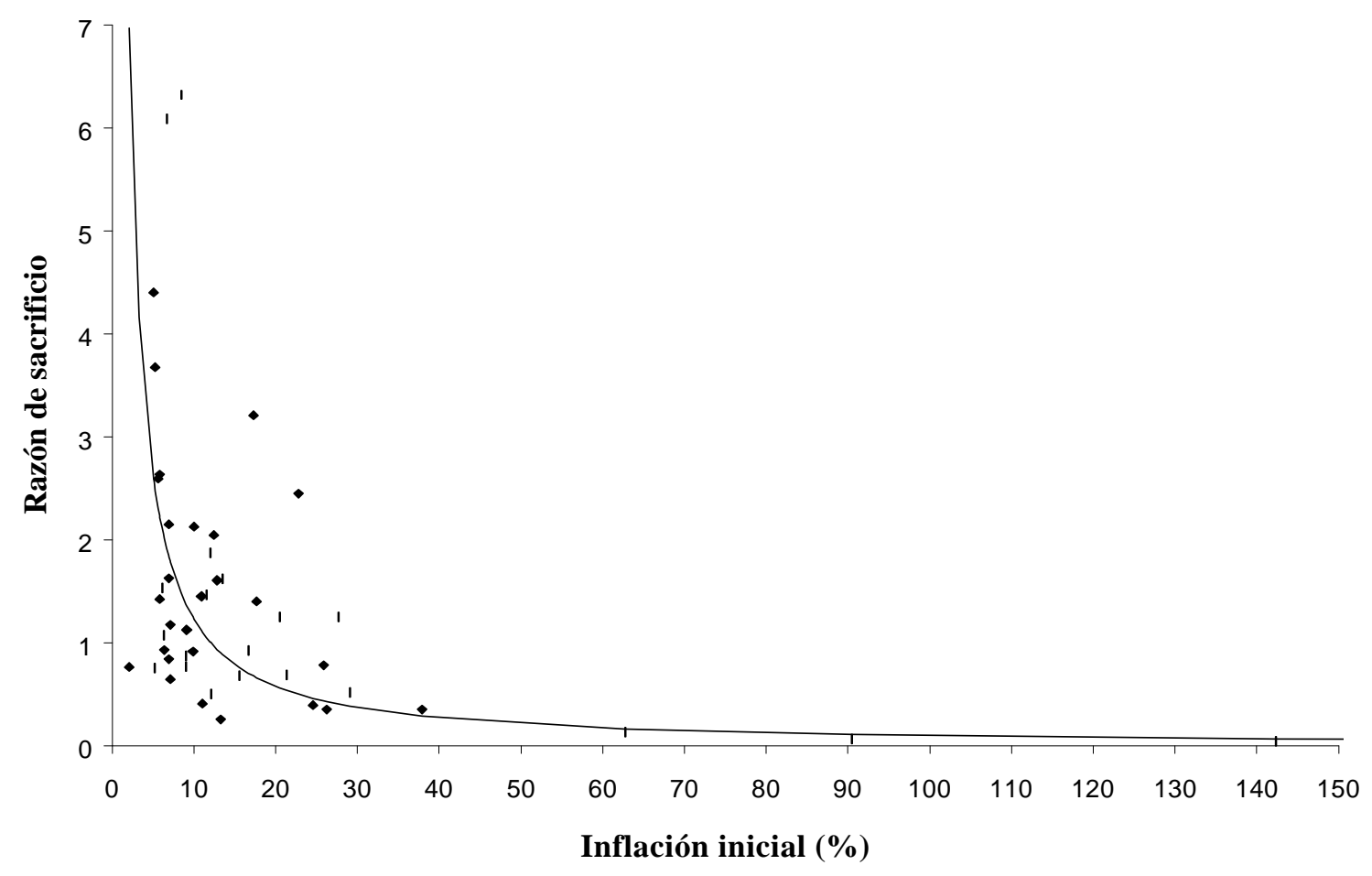

\section{Duradón}

Al analizar la relación entre la duración de los episodios desinflacionarios y el coeficiente de sacrificio, se encontró una relación inversa entre estas dos variables (ver el cuadro 2 y la gráfica 5). Este resultado apoya la proposición altemativa que implica que una desinflación rápida es, manteniendo todo lo demás constante, menos costosa. 


\section{Gráfica 5}

\section{Duración vs. Razón de sacrificio}

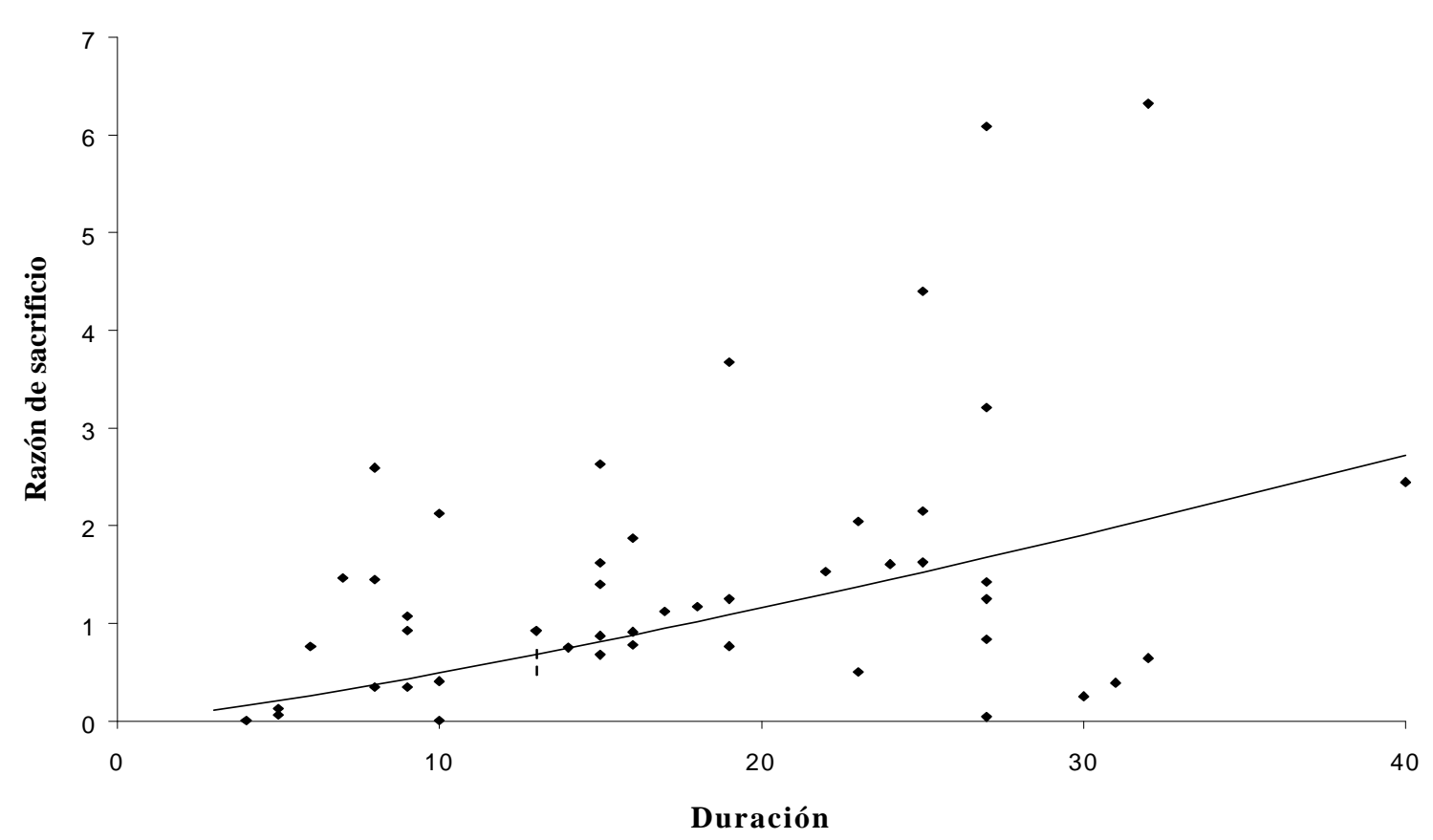

Para determinar de una manera más precisa el impacto de los factores mencionados anteriormente sobre el coeficiente de sacrificio, se estimó una regresión que intenta explicar el logaritmo del coeficiente de sacrificio en función del logaritmo de la velocidad de desinflación, del logaritmo de la duración del episodio desinflacionario, y del logaritmo de la inflación inicial.

Estimamos la regresión para tres muestras distintas. La primera incorpora todos los episodios para los que el coeficiente de sacrificio resulta positivo. En la segunda muestra se toman en cuenta únicamente los episodios de la primera muestra cuya inflación inicial es menor a 40\%. La tercera muestra incorpora únicamente episodios con una inflación inicial menor al 20\%. Los resultados de estas estimaciones se presentan en el cuadro 2. 


\section{Cuadro 2}

\begin{tabular}{|c|c|c|c|c|c|c|c|c|}
\hline \multirow[b]{2}{*}{ constante } & \multicolumn{4}{|c|}{ TODOS LOS CASOS } & \multicolumn{4}{|c|}{ INFLACIÓN INICIAL $<40 \%$} \\
\hline & $\begin{array}{l}0.7894 \\
(-1.16)\end{array}$ & $\begin{array}{r}-0.6745^{\star *} \\
(-6.77)\end{array}$ & $\begin{array}{r}2.7269^{\star *} \\
(7.70)\end{array}$ & $\begin{array}{l}-3.5367^{* *} \\
(-3.9120)\end{array}$ & $\begin{array}{r}-1.1588 \\
(-1.23)\end{array}$ & $\begin{array}{r}-0.3405^{\star *} \\
(-3.34)\end{array}$ & $\begin{array}{r}1.5297^{\star \star} \\
(2.87)\end{array}$ & $\begin{array}{r}-1.1654 \\
(-1.61)\end{array}$ \\
\hline $\begin{array}{l}\text { Velocidad de } \\
\text { desinflación }\end{array}$ & $\begin{array}{r}-0.8984^{* *} \\
(-9.31)\end{array}$ & $\begin{array}{r}-0.9078^{* *} \\
(-13.94)\end{array}$ & & & $\begin{array}{r}-0.7454^{*} \\
(-2.28)\end{array}$ & $\begin{array}{r}-0.6064^{\star *} \\
(-5.24)\end{array}$ & & \\
\hline $\begin{array}{l}\text { Inflación } \\
\text { inicial }\end{array}$ & & & $\begin{array}{r}-1.0944^{\star *} \\
(-9.17)\end{array}$ & & $\begin{array}{r}0.2159 \\
(0.58)\end{array}$ & & $\begin{array}{r}-0.5565^{*} \\
(-2.64)\end{array}$ & \\
\hline $\begin{array}{l}\text { Duración del } \\
\text { periodo } \\
\text { desinflacionario }\end{array}$ & $\begin{array}{r}0.0437 \\
(0.16)\end{array}$ & & & $\begin{array}{r}1.2299^{* *} \\
(2.80)\end{array}$ & $\begin{array}{r}0.0645 \\
(0.20)\end{array}$ & & & $\begin{array}{r}0.4916 \\
(1.83)\end{array}$ \\
\hline $\begin{array}{l}\text { R2 } \\
\text { R2 ajustada }\end{array}$ & $\begin{array}{l}0.77 \\
0.76 \\
\end{array}$ & $\begin{array}{l}0.77 \\
0.76 \\
\end{array}$ & $\begin{array}{l}0.70 \\
0.70 \\
\end{array}$ & $\begin{array}{l}0.23 \\
0.21 \\
\end{array}$ & $\begin{array}{l}0.34 \\
0.29 \\
\end{array}$ & $\begin{array}{l}0.33 \\
0.31 \\
\end{array}$ & $\begin{array}{l}0.19 \\
0.17 \\
\end{array}$ & $\begin{array}{l}0.09 \\
0.06 \\
\end{array}$ \\
\hline & INFLAC & $\mathrm{NINICIAL}<$ & & & & & & \\
\hline constante & $\begin{array}{r}-1.3213 \\
(-0.97)\end{array}$ & $\begin{array}{r}-0.3554 \\
(-1.44)\end{array}$ & $\begin{array}{r}1.2948 \\
(1.64)\end{array}$ & $\begin{array}{r}-0.7129 \\
(-0.92)\end{array}$ & & & & \\
\hline $\begin{array}{l}\text { Velocidad de } \\
\text { desinflación }\end{array}$ & $\begin{array}{r}-0.8101 \\
(-1.76)\end{array}$ & $\begin{array}{r}-0.6115^{\star *} \\
(-2.78)\end{array}$ & & & & & & \\
\hline $\begin{array}{l}\text { Inflación } \\
\text { inicial }\end{array}$ & $\begin{array}{r}0.3023 \\
(0.58)\end{array}$ & & $\begin{array}{r}-0.4395 \\
(-1.24)\end{array}$ & & & & & \\
\hline $\begin{array}{l}\text { Duración del } \\
\text { periodo }\end{array}$ & $\begin{array}{r}0.0326 \\
(0.09)\end{array}$ & & & $\begin{array}{r}0.3810 \\
(1.29)\end{array}$ & & & & \\
\hline desinflacionario & & & & & & ${ }^{* *} \mathrm{~S}$ & $\begin{array}{l}\text { nificativo } \\
\text { nificativo }\end{array}$ & \\
\hline $\begin{array}{l}\text { R2 } \\
\text { R2 ajustada }\end{array}$ & $\begin{array}{l}0.20 \\
0.12\end{array}$ & $\begin{array}{l}0.18 \\
0.16\end{array}$ & $\begin{array}{l}0.07 \\
0.04\end{array}$ & $\begin{array}{l}0.05 \\
0.02\end{array}$ & & & & \\
\hline
\end{tabular}

Como se puede apreciar en el cuadro 2 (y en las gráficas 3 y 4), si consideramos todos los casos de episodios con razones de sacrificio positivas, se observa una relación inversa significativa entre la velocidad de desinflación y el coeficiente de sacrificio. El mismo fenómeno se da entre la inflación inicial y el coeficiente de sacrificio. El resultado anterior era de esperarse ya que existe una alta correlación (0.96) entre la velocidad de desinflación y la inflación inicial en la primera muestra estimada. Es por esta razón por lo que no se incluyeron las dos variables en una misma regresión, evitando así problemas de multicolinealidad. 
En lo que respecta a la relación entre el coeficiente de sacrificio, la velocidad de desinflación, y la duración del episodio, observamos que la velocidad de desinflación es significativa para explicar el coeficiente de sacrificio, pero la duración no lo es. Sin embargo, al considerar únicamente la duración para explicar el coeficiente de sacrificio resulta que sí existe una relación positiva y estadísticamente significativa entre las dos variables, como se vio en la gráfica 5.

Al considerar únicamente episodios con inflaciones iniciales menores al 40\%, se reduce la correlación (a menos de 0.8) entre la velocidad de desinflación y la inflación inicial, por lo que se incluyeron estas dos variables, además de la duración del periodo de desinflación, como variables explicativas del coeficiente de sacrificio. Como se puede ver en el cuadro 2, los resultados son menos contundentes que en el caso de la muestra anterior. De nuevo, únicamente la velocidad de desinflación resulta significativa. Al considerar cada una de las variables explicativas por separado, la duración deja de ser una variable explicativa de la razón de sacrificio y únicamente la velocidad de desinflación y la inflación inicial siguen siendo significativas para explicar el coeficiente de sacrificio en esta regresión.

Los resultados se debilitan aún más cuando se consideran únicamente los episodios con inflación inicial menor a 20\%. Al intentar explicar el coeficiente de sacrificio por medio de la velocidad de desinflación, la inflación inicial y la duración en la inflación, ninguna de las variables es significativa. Al considerar las variables explicativas por separado, únicamente la velocidad de desinflación resulta estadísticamente significativa. Estos resultados indican que para inflaciones menores al 20\%, la duración y la inflación inicial dejan de tener una relación significativa con el coeficiente de sacrificio, siendo únicamente la velocidad de desinflación la que lo afecta.

La debilitación de la relación entre las variables explicativas y la razón de sacrificio, que se observa al considerar muestras subsecuentes de episodios con menores inflaciones iniciales, se puede apreciar en los valores del estadístico $\mathrm{R}^{2}$ para las regresiones del cuadro 2 . Con respecto a la regresión que incluye a la velocidad de desinflación únicamente como variable explicativa, se observa que al pasar de la primera a la segunda muestra la $\mathrm{R}^{2}$ cae en más de 40 puntos porcentuales. Esto es, aunque existe una relación estadísticamente significativa entre la razón de sacrificio y la velocidad de desinflación en las dos muestras, esta variable explica 40\% menos de las variaciones en la razón de sacrificio cuando incluimos solamente episodios con inflaciones iniciales menores a $40 \%$. Al pasar de la segunda a la tercera muestra se observa que la $\mathrm{R}^{2}$ se reduce a casi la mitad.

De modo que al considerar muestras de episodios con inflaciones iniciales menores, se reducen fuertemente los valores de $\mathrm{R}^{2}$ en cada ecuación. De lo anterior concluimos que la hipótesis de Sargent 
(1983), que dice que una mayor velocidad de desinflación implica menores costos, se cumple solo en el caso de desinflaciones que parten de niveles de inflación moderados a altos. Para los casos de desinflaciones que parten de una inflación inicial menor al 20\% con otros los factores que determinan el valor de la razón de sacrificio.

\section{I.3 La desinflación y el régimen cambiario}

En este apartado se analiza el impacto de los regímenes cambiarios adoptados durante los episodios desinflacionarios sobre la relación entre el coeficiente de sacrificio y la velocidad de desinflación. El objetivo es identificar si existe una relación entre el régimen cambiario que hayan adoptado distintos países en su esfuerzo por reducir la inflación y el coeficiente de sacrificio asociado a este régimen. Como ya vimos anteriormente existe una relación estrecha entre la velocidad de desinflación y el coeficiente de sacrificio independientemente del nivel de la inflación inicial. En este apartado se analiza además si la elección de un régimen cambiario en particular puede afectar la velocidad de desinflación partiendo de una misma inflación inicial. Finalmente, el análisis se lleva a cabo considerando únicamente los periodos desinflacionarios que presentaron coeficientes de sacrificio positivos.

El régimen cambiario asociado a cada episodio fue determinado con base en las clasificaciones del FMI6. Se asoció un tipo de cambio fijo a los episodios donde el régimen cambiario del país en cuestión, durante el periodo relevante, fue clasificado como fijo respecto a cualquier moneda o canasta de monedas por esta publicación. Los regímenes cambiarios clasificados como pertenecientes al Sistema Monetario Europeo fueron clasificados como tipos de cambio fijo. Similarmente, únicamente se le asoció la flotación a aquellos episodios cuya clasificación en esta publicación es de "free float". Todas las demás clasificaciones en esta publicación fueron asociadas a tipo de cambio flexible.

\section{El cofidientedesacificioye régimen cambianio}

En la gráfica 6 se presenta la relación entre la inflación inicial y el coeficiente de sacrificio observada para los episodios de la muestra, bajo distintos regímenes cambiarios. Como se puede observar, el coeficiente de sacrificio tiende a disminuir conforme aumenta la inflación inicial, independientemente

\footnotetext{
${ }^{6}$ Ver International Monetary Fund, ExdhangeArrangementsandExhangeRestridions
} 
del régimen cambiario. Sin embargo, para los episodios que se llevaron a cabo bajo flotación, el coeficiente de sacrificio promedio resulta mayor cuando la inflación inicial se encuentra entre 10\% y $20 \%$ que cuando ésta es menor al $10 \%$.

\section{Gráfica 6}

\section{Inflación inicial vs. Razón de sacrificio con distintos regímenes cambiarios}

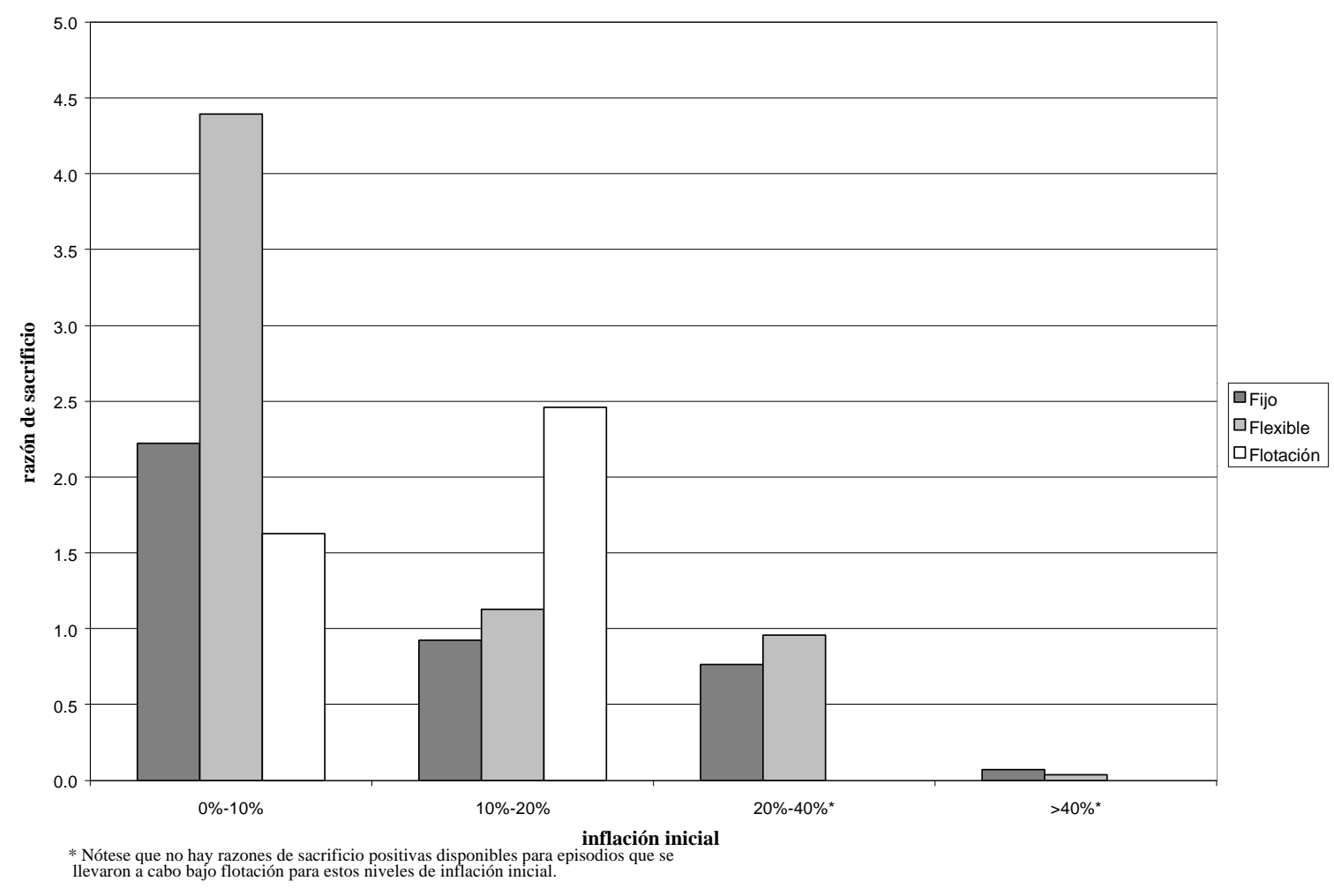

En general, se observa que el valor del coeficiente de sacrificio resulta menor para aquellos episodios que se llevaron a cabo bajo tipo de cambio fijo. Aunque el anterior no es el caso para desinflaciones que empezaron con una inflación inicial menor al 10\%, si lo es tanto para desinflaciones que comienzan de una inflación entre 10 y 20\%, como entre 20 y $40 \%$.

Existen varias razones que explican el resultado anterior. En primer lugar, es importante destacar que la sostenibilidad de largo plazo de la desinflación es una cuestión relevante para las desinflaciones implementadas bajo un régimen de tipo de cambio fijo. Esto es, se puede dar el caso que la fijación del tipo de cambio permita que la inflación caiga durante la desinflación, sin embargo, al no ser la 
desinflación sostenible, la inflación se revierte por arriba de la inflación inicial. Como se mencionaba anteriormente, algunos de los episodios en donde la inflación posterior se revierte por arriba de la inflación inicial están asociados a razones de sacrificio negativas. Sin embargo, existen casos con tipo de cambio fijo donde la razón de sacrificio resulta positiva y la desinflación no sostenible. Por lo tanto, es importante calificar el resultado de la gráfica 6 por el hecho de que algunos episodios con tipo de cambio fijo pueden haber sido no sostenibles en el largo plazo. En base a los resultados de los cuadros A-1 a A-4 del apéndice estadístico, encontramos que, para desinflaciones implementadas bajo tipo de cambio fijo, la inflación posterior al episodio se revierte por arriba de la inicial en los siguientes casos: Argentina (1972:2-1973:3), Argentina (1984:3-1986:3), México (1983:2-1984:3), y México (1987:11993:4). Además, observamos que para cada uno de estos episodios la razón de sacrificio resulta cercana a cero.

Por lo anterior, en la gráfica 7 presentamos el mismo ejercicio excluyendo aquellos episodios bajo tipo de cambio fijo cuya sostenibilidad resulta dudosa. Como se puede observar el resultado de la gráfica 6 no se altera significativamente. 


\section{Gráfica 7}

Inflación inicial vs. Razón de sacrificio

con distintos regímenes cambiarios

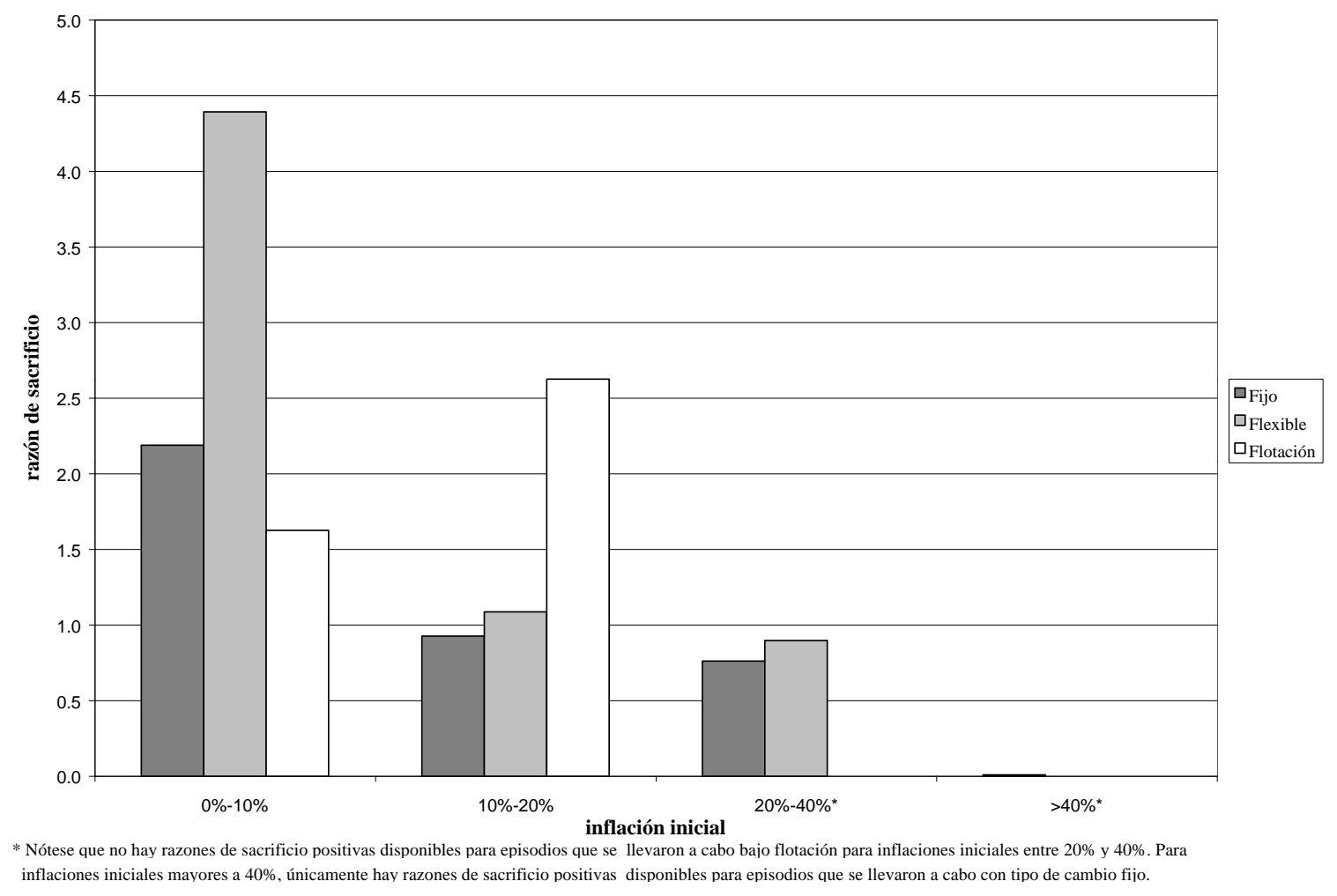

En la introducción a este trabajo mencionábamos a la credibilidad de la autoridad monetaria como uno de los determinantes del costo asociado a la desinflación. No es difícil interpretar la regularidad empírica observada aquí con respecto al régimen de tipo de cambio fijo, a la luz de aquella observación. En un programa desinflacionario construido con base en un ancla cambiaria, el grado de compromiso de la autoridad monetaria con el objetivo inflacionario depende en gran medida de su capacidad de mantener fijo al tipo de cambio. Bajo estas circunstancias el compromiso de la autoridad monetaria tiene mayor visibilidad que en el caso en el que el compromiso solo se refleja en la manera en que esta responde a las desviaciones entre las expectativas de inflación y el objetivo. Por lo tanto, es natural pensar que la autoridad monetaria logra ganancias de credibilidad en la medida en la que es capaz de mantener la regla cambiaria. Estas ganancias se observan en una mayor velocidad de convergencia de la expectativa de inflación al objetivo inflacionario.

Los casos que más se apegan al razonamiento anterior son los de los países europeos que redujeron la inflación a partir de niveles moderados. Para la mayoría de estos países la fijación del tipo de cambio 
resulto un ancla exitosa hasta 1992. Este es el caso de los siguientes episodios: España (1977:21987:2), Italia (1980:4-1987:3), Portugal (1984:1-1987:2), y Reino Unido (1975:1-1978:2). Sin embargo, una vez que se introdujo la flotación, la política de desinflación se mantuvo evitando un repunte de la inflación. Este hecho contrasta con el caso de los países latinoamericanos que al acumular demasiada presión sobre sus paridades fijas tuvieron que dejar flotar el tipo de cambio lo que resultó en una reversión a niveles de alta inflación.

El resultado anterior puede explicarse además mediante las hipótesis sobre el ciclo económico asociado a los procesos de estabilización. Por ejemplo, Kiguel y Liviatan (1992) señalan que al realizar una estabilización utilizando el tipo de cambio como ancla nominal se tiene como resultado una expansión de la economía y posteriormente, probablemente cuando la inflación ya alcanzó sus niveles mínimos, se observa una recesión. Según estos autores, lo contrario ocurre bajo un régimen de flotación, en el cual primero se observa una recesión debido a la restricción monetaria y posteriormente, a medida que se relaja la postura de la política monetaria, se observa una expansión. Por lo tanto, de acuerdo a esta hipótesis, en episodios desinflacionarios donde se utilizaron anclas cambiarias el coeficiente de sacrificio debería ser menor (o hasta negativo) ya que la recesión se pospone hasta después de que se observa la reducción en la tasa de inflación.

\section{La vdocidad dedesinflacióny d régimen cambiario}

En la gráfica 8 se ilustra la relación observada entre la velocidad de desinflación y la inflación inicial, bajo distintos regímenes cambiarios. Como se puede observar, el régimen cambiario no parece tener un impacto relevante sobre la velocidad de desinflación cuando la inflación inicial es menor al 10\%. Conforme aumenta la inflación inicial, aumenta la velocidad de desinflación. Este fenómeno se presenta bajo todos los regímenes cambiarios aunque es más pronunciado para el tipo de cambio fijo. Estos resultados son consistentes con los de la sección anterior. Una mayor velocidad de desinflación se asocia con un menor coeficiente de sacrificio, de la misma forma que los tipos de cambio más rígidos se asocian con un menor coeficiente de sacrificio. Por lo tanto, es consistente que una mayor rigidez cambiaria se asocie a una mayor velocidad de desinflación. 


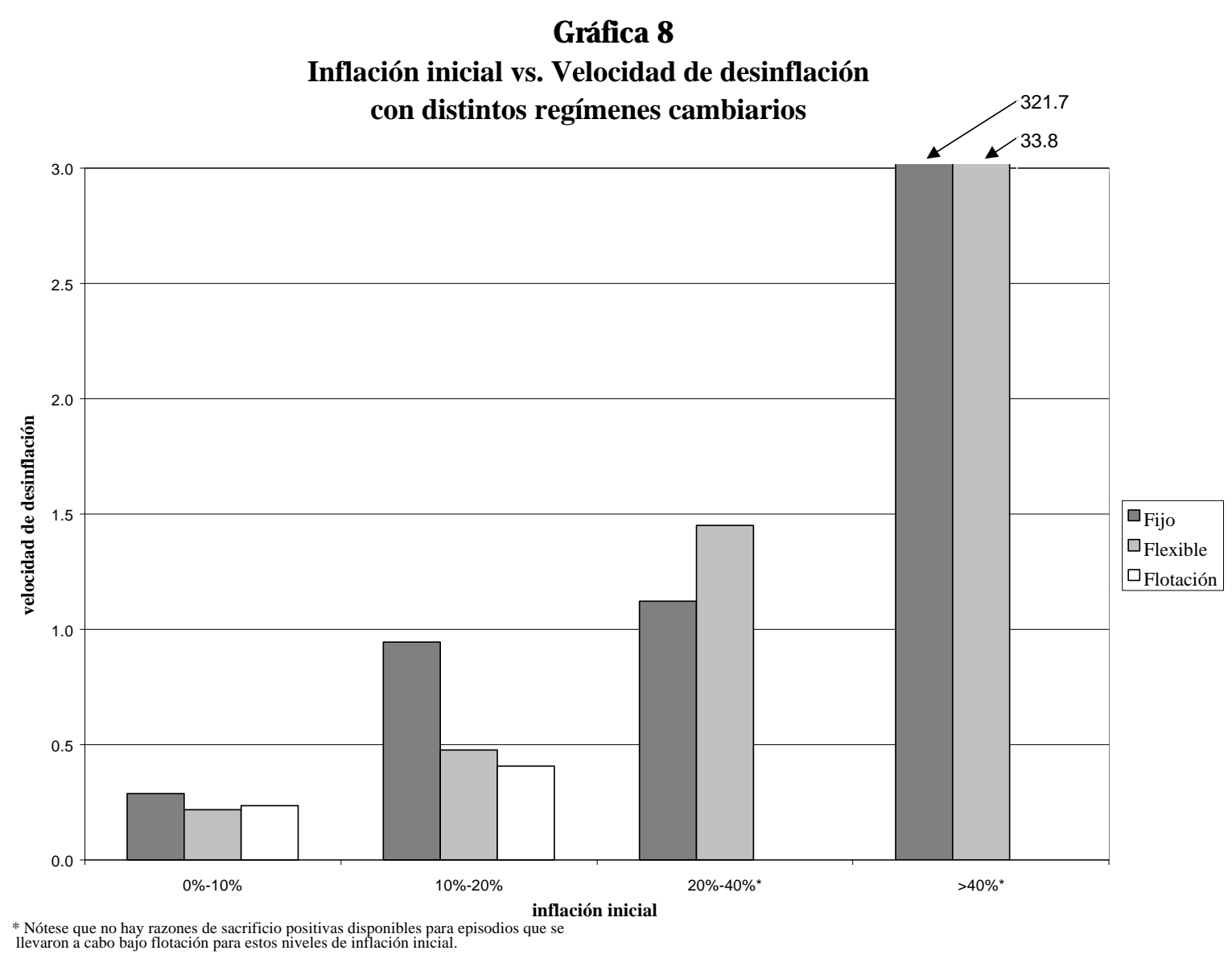

\section{Modelo de desinflación y de los determinantes de su costo}

En esta sección presentamos un modelo macroeconómico que intenta explicar el comportamiento de la tasa de inflación incorporando elementos inerciales, la dinámica del tipo de cambio, y el equilibrio en el mercado laboral. En primer lugar, presentamos las ecuaciones del modelo, para posteriormente resolverlo. Al final llevamos a cabo una serie de ejercicios de simulación para ilustrar como el valor de los parámetros del modelo condicionan el comportamiento de las variables que caracterizan al proceso desinflacionario.

Unmoddodedkinflacón y delos deteminantes di cefiäentedesacifiaio 
Partimos de un modelo en donde la tasa de inflación está determinada por la depreciación cambiaria nominal, la tasa de crecimiento de los salarios, la brecha del PIB con respecto a su nivel potencial, y por un componente inercial7. Esto es,

$$
\pi_{t}=(1-\alpha-\beta) \pi_{t-1}+\alpha s_{t}+\beta w_{t-1}+\gamma y_{t-1}
$$

donde $\pi_{t}=\log P_{t}-\log P_{t-1}$ es la tasa de inflación en $\mathrm{t}$ con $\mathrm{P}_{\mathrm{t}}$ el índice de precios doméstico, $s_{t}=\log S_{t}-\log S_{t-1}$ es la tasa de depreciación cambiaria con St el tipo de cambio nominal, $w_{t}=\log W_{t}-\log W_{t-1}$ es la tasa de crecimiento del salario nominal $\mathrm{W}_{\mathrm{t},} \mathrm{y} y_{t}=\log Y_{t}-\log \bar{Y}$ es la desviación logarítmica del PIB de su nivel potencial $\bar{Y}$.

A partir de la ecuación (I) se observa que en este modelo la inflación presenta persistencia y se acelera siempre que la depreciación cambiaria o la tasa de crecimiento de los salarios sea superior a la inflación rezagada, y ante un aumento de la brecha rezagada del PIB.

Por otro lado, bajo el supuesto de perfecta movilidad de capitales la tasa de interés nominal doméstica está dada por la suma de la tasa de interés internacional, i* y la expectativa actual de la depreciación nominal futura $s_{t+1}^{e}$.Tenemos entonces que

$$
i_{t}=i^{*}+s_{t+1}^{e}
$$

Bajo el supuesto implícito en la ecuación (II) todo aumento en el diferencial de interés provoca una apreciación del tipo de cambio nominal, lo que, de acuerdo a (I), desacelera a la tasa de inflación.

La tasa de crecimiento del salario nominal está determinada por un componente que depende de la inflación rezagada (indexación), y por un factor que responde a presiones en el mercado laboral, las cuales están directamente relacionadas con las desviaciones del PIB de su nivel potencial. Tenemos entonces que:

$$
w_{t}=\pi_{t-1}+\varphi y_{t}
$$

\footnotetext{
${ }^{7}$ De G regorio (1995) presenta un modelo en el que las rigideces en el ajuste de precios y salarios, aunadas a un gobierno que prefiere menos a más inflación, resultan en una tasa de inflación que en el equilibrio sigue un proceso AR(1). Ver también Fischer (1988).
} 
donde $y_{t}=y_{t}-\bar{y}$ mide la brecha entre el logaritmo del PIB observado y el logaritmo del PIB potencial. El nivel del PIB potencial se supone igual a 1 , de modo que $\bar{y}=0$. Suponemos, finalmente, que la brecha del PIB sigue un proceso autorregresivo, que es una función inversa de la tasa de interés real, y una función directa de la brecha del tipo de cambio real con respecto a su equilibrio de largo plazo. De modo que si $\pi_{t+1}^{e}$ es la inflación esperada hoy para el periodo siguiente, tenemos que

$$
y_{t}=\phi y_{t-1}-\delta_{1}\left(i_{t}-\pi_{t+1}^{e}\right)+\delta_{2}\left(\mathrm{q}_{\mathrm{t}}-\overline{\mathrm{q}}\right)
$$

con $0<\phi<1$. En donde el nivel del tipo de cambio real en $t$ viene dado por $q_{t}=\frac{S_{t} P^{*}}{P t}$, con $\mathrm{P}^{*}$ el nivel de precios internacional que se supone igual a la unidad. De modo que toda vez que el tipo de cambio real se encuentre por arriba de su equilibrio de largo plazo existirá un exceso de demanda por bienes no-comerciables, lo que presiona al mercado laboral, provocando un aumento en el salario nominal. Reexpresando a la definición del tipo de cambio real en tasas de crecimiento tenemos que

$$
q_{t}=q_{t-1}+s_{t}-\pi_{t}
$$

Para incorporar el comportamiento de la autoridad monetaria, el modelo se cierra incluyendo la función de reacción del banco central. Se supone aquí que el banco central ajusta su política monetaria, utilizando como instrumento la tasa de interés nominal, toda vez que observa que la expectativa de inflación supera a un objetivo inflacionario predeterminado. En otras palabras, tenemos que la tasa de interés nominal que fija la autoridad monetaria está dada por

$$
i_{t}^{T}=\pi^{o}+\omega\left(\pi_{t+1}^{e}-\pi^{o}\right)
$$

donde $\pi^{0}$ es el objetivo de inflación de la autoridad monetaria, $i_{t}^{T}$ la tasa de interés nominal congruente con este objetivo de inflación, y $\omega$ un parámetro que mide el grado de lasitud de la política monetaria. Esto es, un valor mayor (menor) de $\omega$ implica una política monetaria más (menos) comprometida con el objetivo inflacionario. 
El diagrama 1 intenta resumir la mecánica del modelo ilustrando la manera en que los efectos de la política monetaria son transmitidos a la dinámica de la inflación. Como se puede observar existen cuatro canales a través de los cuales la política monetaria se transmite a los precios.

\section{Diagrama 1}

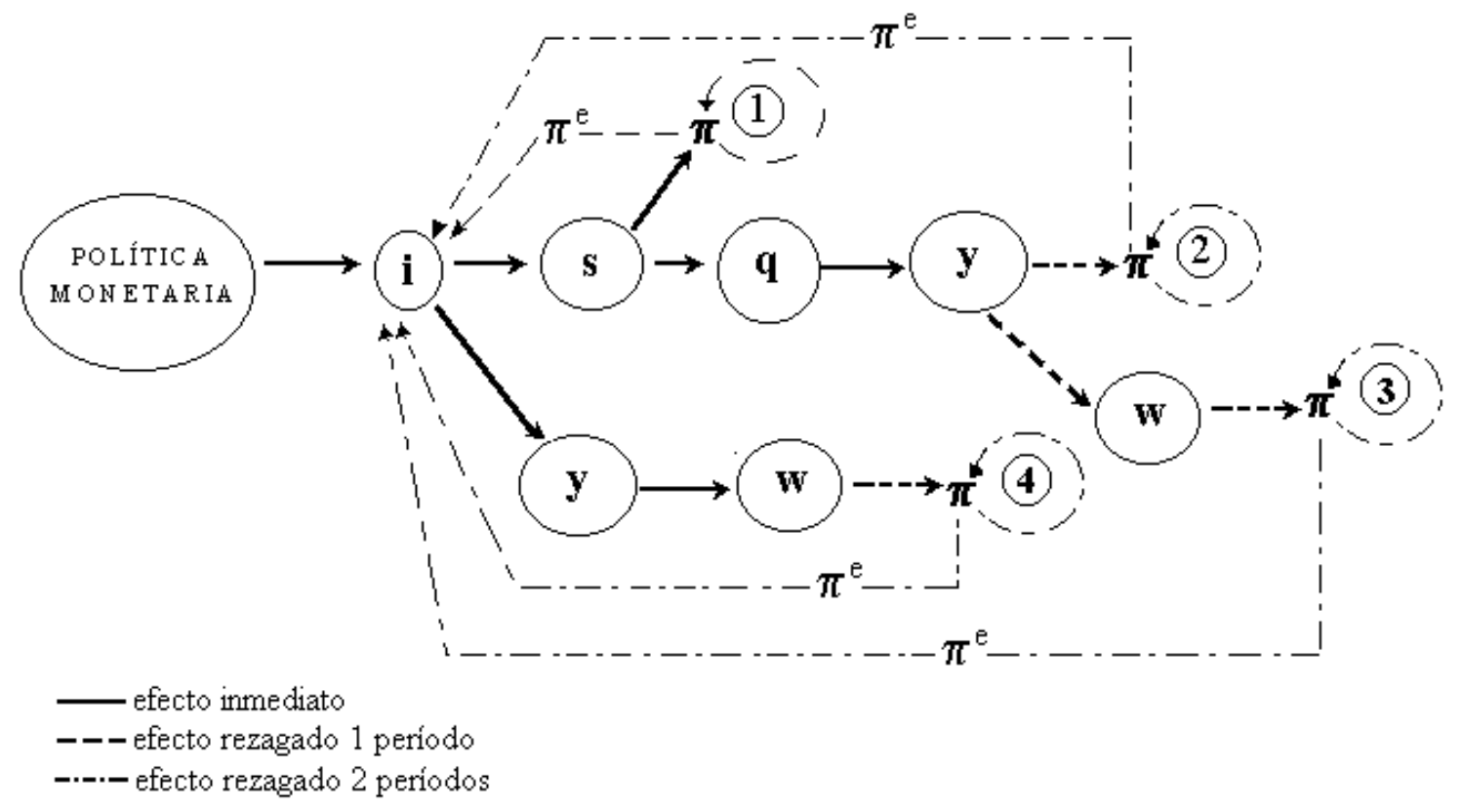

El primer canal funciona a través del efecto que un cambio en la tasa de interés provoca sobre el tipo de cambio, en la ecuación (II). Al apreciarse (depreciarse) el tipo de cambio disminuye (aumenta) la tasa de inflación, esto por medio del efecto que $s_{t}$ tiene sobre $\pi_{t}$ en la ecuación (I).

El segundo canal trabaja a través del efecto que la apreciación cambiaria tiene sobre el nivel del tipo de cambio real. Al apreciarse este por debajo de su nivel de equilibrio de largo plazo, cae el precio relativo de los bienes comerciables con respecto a los no-comerciables. Al encarecerse los bienes nocomerciables cae la demanda agregada provocando una caída en la inflación. 
El canal 3 en el diagrama captura el efecto de la caída en la demanda agregada sobre el mercado laboral. Al disminuir la demanda agregada se crea un exceso de oferta en el mercado laboral, lo que reduce al salario nominal provocando una caída en la inflación.

Finalmente, el canal denotado con el número 4 en el diagrama, captura el efecto directo del aumento en la tasa de interés sobre la demanda agregada (que tal vez funciona a través del efecto sobre los márgenes de ganancia de las empresas). Dado que en la ecuación (I) se supone que cambios en la brecha del PIB demoran un período en afectar a la inflación, el efecto de $y_{t}$ sobre $\pi_{t}$ a través de este canal demora un período.

Nótese que en el diagrama se incluye el efecto que la inflación observada tiene sobre las expectativas. No es difícil observar que en este modelo la expectativa de inflación resulta una función de la inflación actual ${ }^{8}$. Al reducirse la tasa de inflación observada, $\pi_{t+1}^{e}$ cae reduciendo la brecha entre esta y la inflación objetivo. Dada la regla de política de la autoridad monetaria, lo anterior provoca una caída en la tasa de interés nominal9.

Finalmente, en el diagrama se ilustra además el efecto que una caída en la tasa de inflación tiene sobre sí misma, dado el comportamiento inercial implícito en la ecuación (I).

\section{Nótese que:}

$\alpha$ es una medida del cambio en la tasa de inflación provocado por un aumento en el tipo de cambio, del coeficiente de "pass-through",

$\varphi$ es la pendiente de la curva de Phillips,

$\phi$ es el coeficiente de persistencia del PIB, que mide la frecuencia del ciclo económico,

$\delta$ mide la respuesta de la demanda agregada ante un cambio en la tasa de interés real, esto es, la pendiente de la curva IS.

\footnotetext{
${ }^{8}$ Simplemente adelantando la ecuación (I) un período, y tomando expectativa de los dos lados obtenemos $\pi_{t+1}^{e}=(1-\alpha-\beta) \pi_{t}+\alpha s_{t+1}^{e}+\beta w_{t}+\gamma y_{t}$.
} 
D ado que los parámetros anteriores son susceptibles de ser estimados empíricamente, la estructura del modelo hasta aquí descrita puede utilizarse como herramienta para analizar el efecto que los canales de transmisión tienen sobre el proceso que sigue la inflación en el tiempo. Específicamente, es posible analizar la postura de política monetaria del banco central para mantener a la inflación en una trayectoria que converge al objetivo.

\section{Lasoluaón dd moddo}

Bajo el supuesto simplificador de que la tasa de interés internacional es constante e igual a cero, el sistema de ecuaciones (I) a (VI) se puede simplificar de la siguiente manera

$$
\begin{gathered}
\pi_{t}=(1-\alpha-\beta) \pi_{t-1}+\alpha s_{t}+\beta w_{t-1}+\gamma y_{t-1} \\
y_{t}=\phi y_{t-1}-\delta_{1}\left(i_{t}-\pi_{t+1}^{e}\right)+\delta_{2}\left(\mathrm{q}_{\mathrm{t}}-\overline{\mathrm{q}}\right) \\
w_{t}=\pi_{t-1}+\varphi\left(y_{t}-\overline{\mathrm{y}}\right) \\
s_{t+1}^{e}=\omega \pi_{t+1}^{e}-(\omega-1) \pi^{o} \\
q_{t}=q_{t-1}+s_{t}-\pi_{t} \\
\pi_{t+1}^{e}=E_{t}\left(\pi_{t+1}\right) \\
s_{t+1}^{e}=E_{t}\left(s_{t+1}\right)
\end{gathered}
$$

El sistema dinámico (1)-(7) consta de 7 ecuaciones con 7 variables endógenas $\pi_{t}, s_{t}, y_{t}, w_{t}, q_{t}, \pi_{t+1}^{e}, s_{t+1}^{e}, 4$ variables predeterminadas $\pi_{t-1}, y_{t-1}, w_{t-1}, q_{t-1}, \mathrm{y} 3$ valores exógenos

\footnotetext{
${ }^{9}$ En el diagrama las líneas continuas denotan transmisión de efectos en el período
} 
$\pi^{o}, \bar{y}, \mathrm{y} \bar{q}$. Existen varios métodos para obtener la forma reducida del sistema, aquí se utiliza el método de la transformada $\mathrm{z}$ móvil unilateral ${ }^{10}$.

A partir de este método de solución se obtiene una relación de comportamiento para $\pi_{\mathrm{t}} \mathrm{y} \mathrm{s}_{\mathrm{t}}$ en función de variables predeterminadas. Puesto que la ecuación (1) es también una relación de comportamiento para $\pi_{\mathrm{t}} \mathrm{y} \mathrm{S}_{\mathrm{t}}$, se construye, a partir de estas dos ecuaciones, un sistema para $\pi_{\mathrm{t}} \mathrm{y} \mathrm{S}_{\mathrm{t}}$ en función de las variables predeterminadas $\pi_{\mathrm{t}-1}, \mathrm{y}_{\mathrm{t}-1}, \mathrm{w}_{\mathrm{t}-1}, \mathrm{y} \mathrm{q}_{\mathrm{t}-1}$. D e esta manera obtenemos:

$$
\begin{aligned}
& \pi_{t}=\pi\left(\pi_{t-1}, y_{t-1}, w_{t-1}, q_{t-1}\right) \\
& s_{t}=s\left(\pi_{t-1}, y_{t-1}, w_{t-1}, q_{t-1}\right)
\end{aligned}
$$

Una vez obtenida la solución para $\pi_{\mathrm{t}} \mathrm{y} \mathrm{S}_{\mathrm{t}}$, a partir de la ecuación (5) se obtiene la solución para $\mathrm{q}_{\mathrm{t}}$ en función de variables predeterminadas.

$$
q_{t}=q\left(\pi_{t-1}, y_{t-1}, w_{t-1}, q_{t-1}\right)
$$

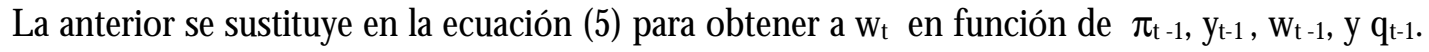

$$
w_{t}=w\left(\pi_{t-1}, y_{t-1}, w_{t-1}, q_{t-1}\right)
$$

Finalmente, se adelanta la ecuación (1) un período, tomando la expectativa condicional en t de los dos lados. Se sustituyen los valores de $\pi_{\mathrm{t}} \mathrm{y} \mathrm{w}_{\mathrm{t}}$ en la ecuación resultante, obteniéndose una ecuación en las variables $y_{t}, \pi_{t+1}^{e}, s_{t+1}^{e}$.

Esta última ecuación, junto con (2) y (4) forman un sistema de 3 ecuaciones en estas variables. Al resolver el sistema se obtienen las formas reducidas de $y_{t}, \pi_{t+1}^{e}, s_{t+1}^{e}$ en función de las variables predeterminadas.

$$
\begin{aligned}
& \pi_{t+1}^{e}=\pi\left(\pi_{t-1}, y_{t-1}, w_{t-1}, q_{t-1}\right) \\
& s_{t+1}^{e}=s\left(\pi_{t-1}, y_{t-1}, w_{t-1}, q_{t-1}\right) \\
& y_{t}=y\left(\pi_{t-1}, y_{t-1}, w_{t-1}, q_{t-1}\right)
\end{aligned}
$$

Para ilustrar las características del modelo en equilibrio a continuación llevamos a cabo una serie de ejercicios de simulación a partir de la calibración del modelo.

10 Véase Pérez-Porrúa (1984). 


\section{Ejeciaios deSimilacón}

A continuación llevamos a cabo una serie de ejercicios de simulación con el objeto de estudiar como la estructura del modelo condiciona la relación entre la velocidad de desinflación, la inflación inicial, y el coeficiente de sacrificio. Intentamos probar si la estructura del presente modelo es suficiente para explicar las regularidades empíricas encontradas en la primera parte del trabajo.

Suponemos que la economía parte de una inflación inicial de 16\%, y que la autoridad monetaria se propone un objetivo de inflación del $5 \%$, en un intervalo de tiempo determinado por el grado de intensidad de la política monetaria. El objetivo es evaluar el costo asociado a distintas intensidades de la política monetaria.

De modo que en estos ejercicios la desinflación es de 11 puntos porcentuales, partiendo de una inflación inicial de $16 \%, \pi_{0}=0.16$, a un objetivo de inflación de $5 \%, \pi^{0}=0.05$. Suponemos además que tanto el nivel del PIB potencial como el equilibrio de largo plazo del tipo de cambio real son iguales a 1 , de modo que $\bar{y}=0$ y $\bar{q}=1$.

Dado el modelo descrito anteriormente, y puesto que $\omega$ está fijo a lo largo de cada simulación, la función de reacción del banco central implica que cada vez que $\pi_{t+1}^{e}$ este por arriba de $\pi^{0}$ la autoridad monetaria reduce la oferta monetaria provocando un aumento en la tasa de interés nominal. El número de puntos de aumento en la tasa de interés depende del valor de $\omega$, el grado de intensidad de la política monetaria. Esto es, $\omega$ es una medida de la agresividad con que la autoridad monetaria persigue el objetivo de inflación. Mientras mayor sea $\omega$ mayor es el compromiso de la autoridad con la desinflación.

Para llevar a cabo estos ejercicios calibramos los parámetros del modelo con base en supuestos razonables observados en la experiencia desinflacionaria reciente de varias economías como Gran Bretaña y Australia ${ }^{11}$

- Para la curva IS, fijamos $\delta_{1}=0.0008, \delta_{2}=0.03$, y $\phi=0.8$. Esto implica que la elasticidad de la demanda agregada a la tasa de interés real es poco significativa, y que una

\footnotetext{
${ }^{11}$ Los valores de los parámetros se tomaron valores dentro de un rango determinado por estudios para otros países, véase Batini y Haldane (1999).
} 
apreciación real del 10\% provoca una brecha negativa del producto igual a 0.3 por ciento en el corto plazo, y una brecha de 1.5 por ciento en el largo plazo.

- Para la ecuación de inflación suponemos $\alpha=\beta=0.2$. Estos valores implican que una depreciación del 10\% en el tipo de cambio nominal (o un aumento de la inflación salarial) provoca un alza en la inflación de 2 puntos porcentuales en el mismo trimestre (y para los salarios en el trimestre que sigue), y 5 puntos porcentuales en el largo plazo.

- Con respecto a la ecuación de crecimiento en los salarios, suponemos que $\varphi=0.2$ lo que implica que un aumento de $1 \%$ en la demanda agregada aumenta la inflación salarial en 0.2 puntos porcentuales.

En la gráfica 9 mostramos, para dos intensidades de la política monetaria, la evolución de las variables endógenas al modelo, bajo los supuestos descritos anteriormente. Podemos observar que para ambas intensidades de política monetaria la tasa de inflación parte de 16\% para descender de manera continua al objetivo inflacionario del 5\%. Se observa, además, que mientras mayor es el compromiso del banco central con el objetivo, mientras mayor es $\omega$, la inflación converge más rápidamente al objetivo. De esta manera una política monetaria no tan comprometida con el objetivo de inflación, donde $\omega=1.9$, provoca que la economía alcance el objetivo en alrededor de 22 trimestres (5 años y medio). En cambio, una política monetaria agresiva, donde $\omega=5.9$, hace que la economía alcance el objetivo en alrededor de 14 trimestres (3 años y medio). Por lo tanto, un mayor compromiso con la desinflación puede reducir el tiempo de convergencia a la inflación objetivo en alrededor de 8 trimestres (2 años). 


\section{Gráfica 9}
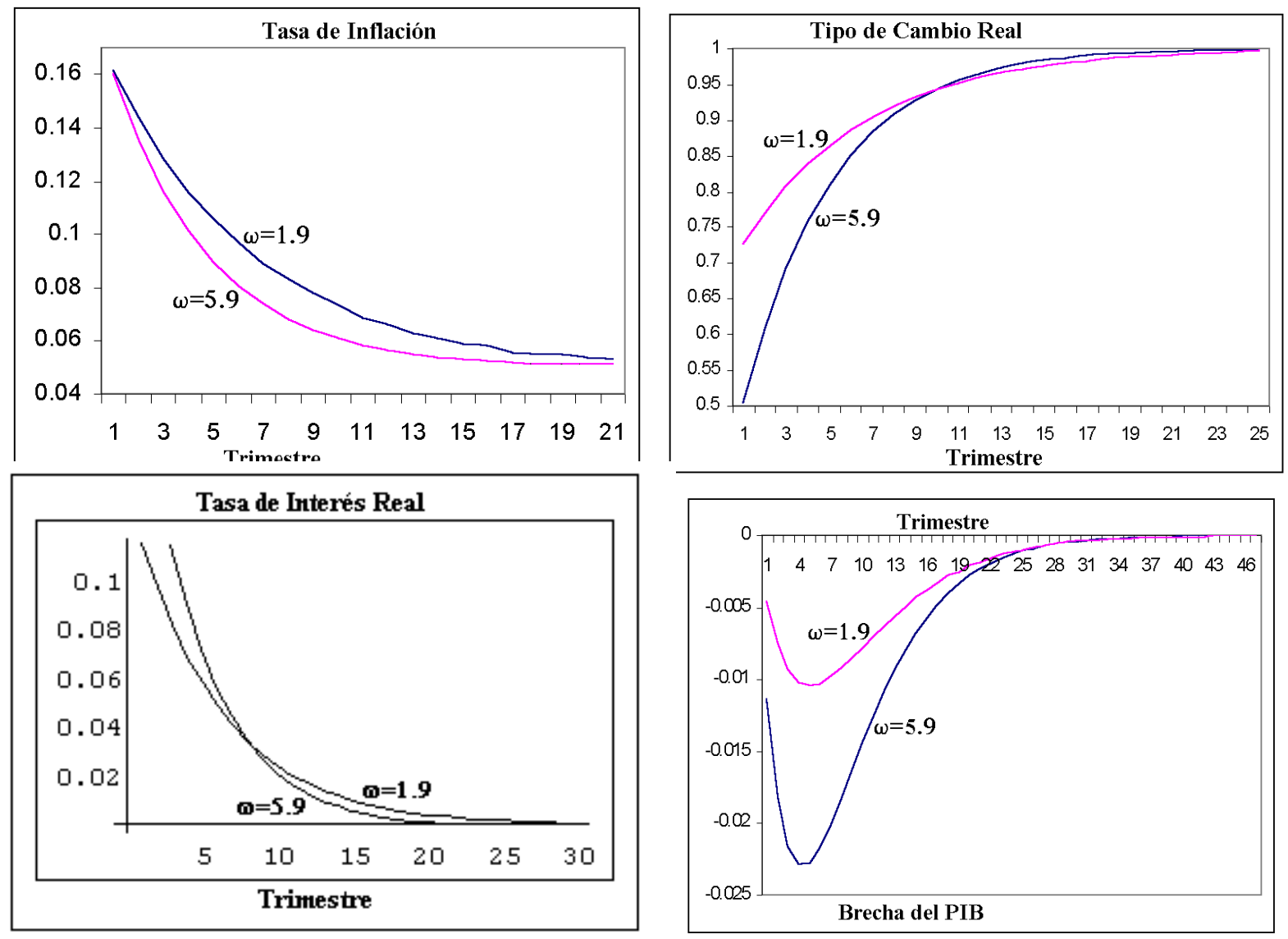

En la trayectoria que conduce al nuevo equilibrio el tipo de cambio real se aprecia inicialmente, con respecto al equilibrio de largo plazo, para después depreciarse a una tasa decreciente hasta converger el equilibrio en $\bar{q}=1$. En el caso de la política monetaria relativamente laxa la máxima apreciación del tipo de cambio real resulta de poco más del 25\%. Mientras que para la política relativamente agresiva esta resulta de más del 50\%. Un tipo de cambio real apreciado implica un exceso de oferta en el mercado laboral doméstico. Por lo tanto, en la trayectoria al equilibrio, aunque el salario nominal está aumentando, el salario real cae. Esto último aunado a la brecha negativa del PIB, resulta en una tasa de inflación a la baja.

Tanto el aumento en la tasa de interés real, como la apreciación real mantienen al PIB por debajo de su nivel potencial durante todo el trayecto al nuevo equilibrio. La pérdida acumulada en el PIB es igual 
al área entre la curva correspondiente y el eje de las abscisas. El coeficiente de sacrificio resulta de dividir esta área por los puntos de desinflación. Para la política monetaria relativamente laxa, $\omega=1.9$, la perdida acumulada resulta de 3 puntos del PIB anual. Para la política agresiva, $\omega=5.9$, de 7 puntos del PIB anual. Las líneas correspondientes a la brecha del PIB para distintos valores de $\omega$ se cruzan en un punto cercano al nivel del PIB potencial (dado que la inflación converge más rápido al objetivo cuando $\omega=5.9$, el PIB debe converger más rápido al potencial). Este cruce tan cerca del punto de convergencia implica que el área por arriba de la curva que corresponde a un valor mayor de $\omega$ sea mayor ${ }^{12}$. De modo que en este modelo el coeficiente de sacrificio aumenta con el valor de $\omega$.

En el cuadro 3 presentamos un resumen de la evolución de las variables que caracterizan al episodio desinflacionario para distintos grados de intensidad de la política monetaria. En cada ejercicio contabilizamos tanto el número de períodos que dura la desinflación, $\mathrm{T}$, como la velocidad de desinflación en puntos por trimestre, la suma de las desviaciones del PIB con respecto al potencial, y la pérdida acumulada en puntos del PIB, $\sum_{0}^{T} y_{t}$. El coeficiente de sacrificio resulta de dividir este último valor por la caída en la inflación $\pi_{0}-\pi^{\circ}$.

En todos los ejercicios la inflación inicial es igual a 16\%. De modo que tenemos que por ejemplo, en el caso de $\omega=1.9$, le toma 4 períodos a la economía llegar a una inflación de 12\%. Además, dado que la pérdida acumulada correspondiente resulta igual a 0.8 puntos del PIB, el coeficiente de sacrificio es igual a 0.21 en este caso. Siguiendo este razonamiento encontramos que, bajo esta postura de política monetaria, toma 26 períodos reducir la inflación hasta el objetivo de 5\%. La perdida acumulada resulta de 4.1 puntos del PIB, lo que en este caso hace que la razón de sacrificio tome un valor de 0.37 .

\footnotetext{
${ }^{12}$ Nótese como este podría muy bien no ser el caso de cruzarse estas curvas en algún punto más hacia la izquierda de la gráfica.
} 


\section{Cuadro 3}

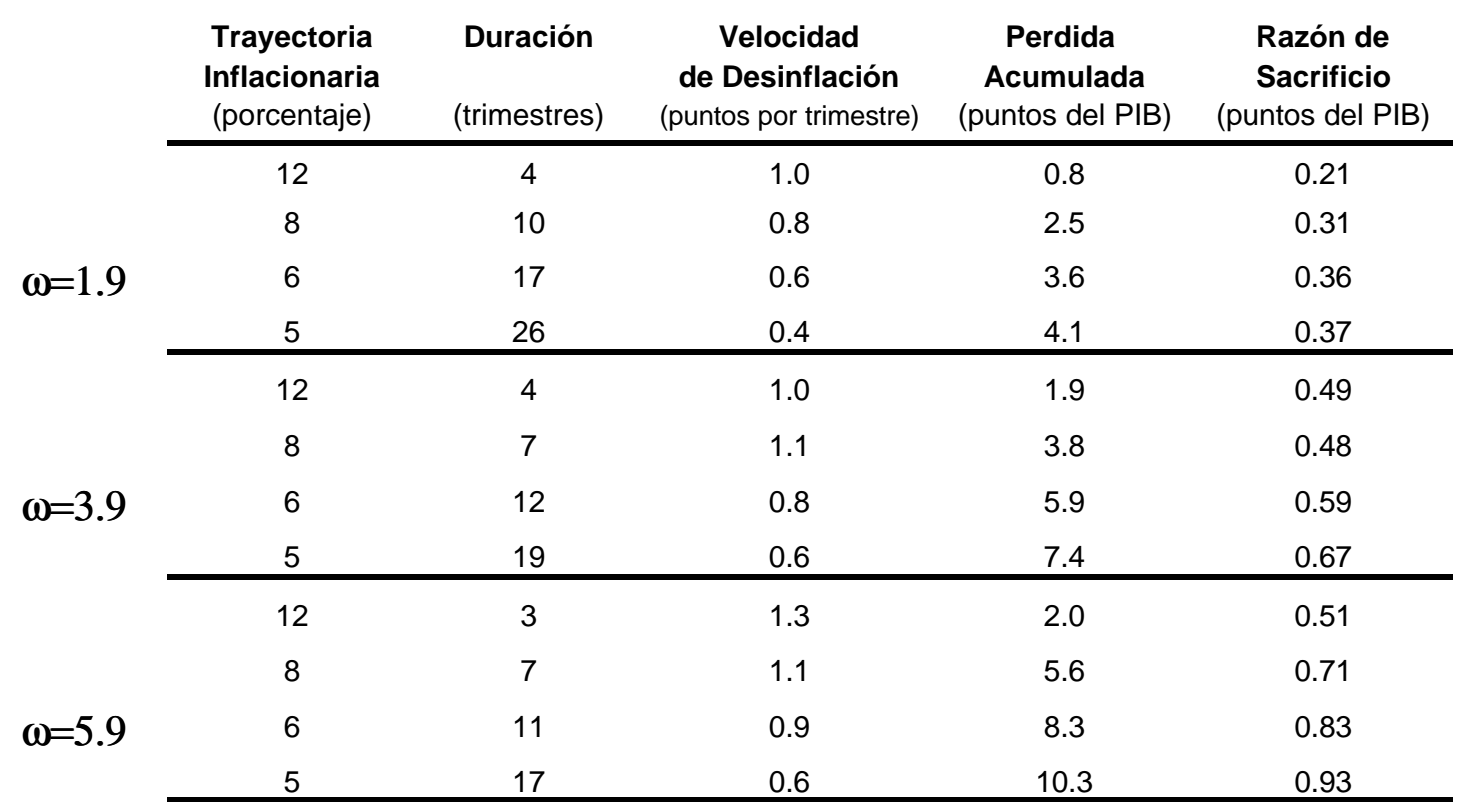

D e estas simulaciones sobresalen los siguientes resultados:

- Aumentar la velocidad de desinflación en un tercio duplica la razón de sacrificio.

- La razón de sacrificio fluctúa entre 0.21 y 0.93 puntos del PIB anual por punto de desinflación.

De modo que la estructura del modelo condiciona a una relación directa entre la velocidad de desinflación y el coeficiente de sacrificio. Esto se debe a que el elemento que juega un papel principal en el modelo es la estructura de contratos laborales con duración de más de un período. Lo que implica que por muy rápido que la autoridad monetaria quiera reducir la tasa de inflación, esta no convergerá sino lentamente al objetivo inflacionario. Esto es, puesto que $\pi_{t+1}^{e}$ depende de $\pi_{t}$ en la misma forma en que $\pi_{t}$ depende de $\pi_{t-1}$, aunque la autoridad monetaria haya obtenido ganancias significativas en el frente de la inflación, los agentes esperan que esta disminuya al mismo ritmo al que ha venido disminuyendo en el pasado. 
El resultado que aquí obtenemos no es más que un reflejo del hecho de que siempre que existen rigideces, ya sea en el mercado de bienes o en el de trabajo, es menos costoso implementar una desinflación gradual. Esto es, puesto que transcurre más de un período para que los precios o salarios se vuelvan a negociar, solo una desinflación gradual permite que transcurra el tiempo suficiente para que los precios y salarios se ajusten a la nueva postura de política del banco central. Esta conclusión es semejante a la que obtienen Fischer (1988) y Taylor (1983) para modelos en los que existen contratos laborales con duración de más de un período.

\section{Lainexia salanial ye œeficientedesaciifico}

Hasta ahora hemos estado suponiendo que los asalariados ven hacia atrás a la hora de negociar sus contratos laborales. Esto es, en la ecuación (3) el crecimiento del salario nominal depende de la inflación rezagada. De modo que los asalariados asocian a la inflación esperada para el período siguiente con la observada el período anterior. Vale la pena explorar el efecto, sobre la razón de sacrificio y la velocidad de desinflación, de suponer que los asalariados forman sus expectativas tanto de manera racional como de manera adaptativa.

Para capturar el efecto anterior sustituimos la ecuación (3) por la siguiente ecuación de crecimiento del salario nominal

$$
w_{t}=\sigma \pi_{t-1}+(1-\sigma) \pi_{t+1}^{e}+\varphi\left(q_{t}-\bar{q}\right)
$$

Esta ecuación implica que para determinar el crecimiento en el salario los asalariados toman en cuenta tanto la inflación rezagada como la inflación esperada (supuesto de expectativas racionales) caracterizada por el modelo. En un proceso de reducción de la tasa de inflación este último elemento disminuye la inercia en la inflación salarial. En las simulaciones que siguen, presentadas en el Cuadro 4, llevamos a cabo un ejercicio idéntico al anterior solo que suponiendo13 $\sigma=0.5$.

\footnotetext{
${ }^{13}$ Nótese que hasta el momento hemos estado suponiendo $\sigma=1$.
} 


\section{Cuadro 4}

\begin{tabular}{|c|c|c|c|c|c|}
\hline & $\begin{array}{c}\text { Trayectoria } \\
\text { Inflacionaria } \\
\text { (porcentaje) }\end{array}$ & $\begin{array}{l}\text { Duración } \\
\text { (trimestres) }\end{array}$ & $\begin{array}{c}\text { Velocidad } \\
\text { de Desinflación } \\
\text { (puntos por trimestre) }\end{array}$ & $\begin{array}{c}\text { Perdida } \\
\text { Acumulada } \\
\text { (puntos del PIB) } \\
\end{array}$ & $\begin{array}{c}\text { Razón de } \\
\text { Sacrificio } \\
\text { (puntos del PIB) } \\
\end{array}$ \\
\hline & 12 & 4 & 1.0 & 0.8 & 0.19 \\
\hline & 8 & 8 & 1.0 & 1.8 & 0.22 \\
\hline \multirow[t]{4}{*}{$\omega=1.9$} & 6 & 13 & 0.8 & 2.7 & 0.27 \\
\hline & 5 & 22 & 0.5 & 3.4 & 0.31 \\
\hline & 12 & 3 & 1.3 & 1.3 & 0.32 \\
\hline & 8 & 6 & 1.3 & 3.0 & 0.37 \\
\hline \multirow[t]{4}{*}{$\omega=3.9$} & 6 & 10 & 1.0 & 4.3 & 0.43 \\
\hline & 5 & 16 & 0.7 & 5.7 & 0.52 \\
\hline & 12 & 3 & 1.3 & 2.0 & 0.49 \\
\hline & 8 & 6 & 1.3 & 4.4 & 0.55 \\
\hline \multirow[t]{2}{*}{$\omega=5.9$} & 6 & 9 & 1.1 & 5.7 & 0.57 \\
\hline & 5 & 14 & 0.8 & 7.4 & 0.67 \\
\hline
\end{tabular}

Al comparar los resultados de los cuadros 3 y 4 se puede observar el efecto que las expectativas racionales tienen sobre los costos de la desinflación. Por ejemplo, para $\omega=1.9$ observamos del cuadro 4 que reducir la tasa de inflación de 16 a $12 \%$ implica un costo de 0.21 puntos del PIB por punto de inflación. En el cuadro 3 observamos que el costo asociado a esta desinflación es igual a 0.19 puntos del PIB por punto de inflación. De modo que el coeficiente de sacrificio resulta menor cuando los trabajadores negocian el aumento en el salario nominal en parte en base a la expectativa de inflación resultante del modelo. Generalizando, observamos que lo anterior se cumple para cualquier valor de $\omega$.

El resultado anterior proviene del hecho de que cuando el salario nominal depende tan solo de la inflación rezagada, se introduce mayor inercia en la inflación salarial. Esto es, dado que en el proceso de desinflación la inflación pasada siempre resulta mayor a la actual, y a la esperada para mañana, el crecimiento en el salario nominal tarda más en converger a la inflación objetivo. Lo anterior genera un aumento en los costos de la desinflación. Sin embargo, al elevar el valor del parámetro $\sigma$ el costo de la desinflación disminuye. Este aumento en el valor de $\sigma$ se podría relacionar con aumentos en la intensidad de la política monetaria (aumentos en $\omega$ ), ya que cuando el banco central es más sensible a desviaciones entre la expectativa de inflación y el objetivo, esto se reflejará en una mayor credibilidad de la autoridad monetaria. Lo anterior debe verse reflejado en la formación de expectativas por parte 
de los asalariados. Este efecto se captura aquí por medio de elevar el valor del parámetro $\sigma$. Así, los asalariados corrigen el proceso de formación de expectativas siempre que observan que el banco central está más comprometido con la desinflación.

Como se puede observar en los casos de los cuadros 3 y 4, siempre que nos concentramos en el comportamiento de la razón de sacrificio dentro de uno de los cuadros, observamos que una mayor $\omega$ aumenta la razón de sacrificio. Esto por el efecto de la inercia inflacionaria sobre el ajuste de los precios. Sin embargo, si comparamos los resultados del cuadro 3 con los del 4 encontramos que al aumentar $\omega$ el aumento en la razón de sacrificio no es tan pronunciado, por el efecto de mayor credibilidad generado por el mayor compromiso con el objetivo de inflación. 


\section{Conclusiones}

El análisis presentado en este trabajo caracterizó al proceso desinflacionario estudiando la relación que existe entre la velocidad de desinflación y el costo asociado a ésta estimado, por medio del cálculo del coeficiente de sacrificio. El estudio se llevó a cabo con base en el análisis empírico de la primera parte en donde se analizan los episodios desinflacionarios observados durante los últimos 30 años para una muestra amplia de países.

Los resultados de la primera parte señalan que en promedio los procesos desinflacionarios han tenido costos en términos del producto, y apuntan hacia la existencia de una relación inversa entre el coeficiente de sacrificio y la velocidad de desinflación, la cual disminuye a medida que desciende la inflación inicial. Se comprueba, además, la hipótesis de Ball, Mankiw, y Romer (1988) según la cual en un proceso desinflacionario la relación entre el coeficiente de sacrificio y la inflación inicial es inversa.

En la segunda parte del trabajo presentamos un modelo macroeconómico al que incorporamos los elementos relevantes de los procesos desinflacionarios analizados anteriormente. Ilustramos como el modelo captura los costos asociados a estos procesos por medio del efecto que la desinflación tiene sobre la brecha del producto respecto al nivel potencial. En base al modelo se llevaron a cabo una serie de ejercicios de simulación, a partir de los cuales se observa que el modelo implica una relación directa entre el coeficiente de sacrificio y la velocidad de desinflación. Este resultado se debe a que el modelo no captura el efecto de la postura de política monetaria sobre la credibilidad del objetivo de inflación y la influencia que el banco central ejerce sobre la formación de las expectativas de inflación. Como un acercamiento a capturar este efecto, incorporamos la formación de expectativas que miran hacia delante a la ecuación de determinación del salario nominal. Encontramos que los costos de la desinflación disminuyen a medida que los asalariados forman sus expectativas de manera racional, esto es en base a la propia solución del modelo. Dicho de otra forma, para incorporar el efecto de la mayor credibilidad de la autoridad monetaria alteramos en el modelo el mecanismo de formación de expectativas de los asalariados, de modo tal que cada vez que la autoridad monetaria aumente su compromiso con la desinflación los asalariados lo incorporen al proceso de formación de los salarios formando sus expectativas de inflación de acuerdo con las expectativas generadas por el propio modelo, y poniendo menos énfasis en la inflación pasada. Dado lo anterior, al aumentar el compromiso por parte de la autoridad monetaria con respecto al objetivo de inflación, los asalariados ajustan con mayor rapidez el crecimiento en los salarios de manera acorde con este objetivo. Esto es, a 
diferencia del caso en el que los asalariados basan sus expectativas en la inflación rezagada, ahora los salarios convergen más rápidamente al objetivo, reduciéndose de este modo los costos de la desinflación. Al final, lo que obtenemos es un resultado ambiguo con respecto a la relación entre la velocidad de desinflación y la razón de sacrificio. Esto es, una desinflación rápida bajo expectativas racionales ya no necesariamente implica un costo elevado en producción. 


\section{Referencias}

Ball, L. (1994), "What determines the Sacrifice Ratio?", en Mankiw G. (ed.), "Monetary Policy", Chicago, National Bureau of Economic Research.

Ball L., G. Mankiw y D. Romer (1988), "The New Keynesian Economics and the Output-Inflation Trade-off", Brookings Papers on Economic Activity, Vol. 1

Batini, N. y A. Haldane (1999), "Forward-Looking Rules for Monetary Policy", Working Paper No. 91, Bank of England.

Blanchard, O . (1998), "Optimal Speed of Disinflation: Hungary", en Cottarelli, C. y G. Szapáry (ed.), "Moderate Inflation: The Experience of Transition Economies", Fondo Monetario Internacional.

D e G regorio, J. (1995), "Policy Accommodation and G radual Stabilizations", Journal of Money, Credit and Banking, Vol. 27, No. 3

Fischer, S. (1988), "Real Balances, the exchange rate, and indexation: real variables in disinflation", Q uarterly Journal of Economics.

Hodrick, R.J. y E.C. Prescott (1997), "Postwar U.S. Business Cycels: an Empirical Investigation", Journal of Money, Credit and Banking, 29.

International Monetary Fund, "International Financial Statistics", varios tomos

International Monetary Fund, "Exchange Arrangements and Exchange Restrictions", varios tomos

Kiguel, M. y N. Liviatan (1992), "The Business Cycle Associated with Exchange Rate- Based Stabilizations", The World Bank Economic Review, Vol. 6, No. 2.

Pérez-Porrúa, J.M. (1984), "Solución a una clase general de modelos lineales en diferencias con expectativas racionales", D ocumento de Investigación \#56, Banco de México.

Romer, D . (1991), "O penness and Inflation: Theory and Evidence", NBER Working Paper No. 3936, Diciembre 
Sargent, T. (1983), "Stopping Moderate Inflations: The Methods of Poincare and Thatcher", en D ornbusch, R. y M. Simonsen (ed.), Cambridge, Mass: MIT Press.

Taylor, J.B. (1983), "Union Wage Settlements during a D isinflation", American Economic Review 73, Diciembre. 
Apéndice Estadístico

Cuadro A-1

\begin{tabular}{|c|c|c|c|c|c|c|c|c|c|c|}
\hline País & Inicio & Fin & $\pi$ inicial $(\%)$ & $\pi$ final $(\%)$ & reduccion en $\pi(\%)$ & $\begin{array}{l}\pi \text { del tın a } \angle \text { anos } \\
\text { después de desinf. }\end{array}$ & $\begin{array}{l}\text { duración } \\
\text { (periodos) }\end{array}$ & $\begin{array}{c}\text { velocidad de } \\
\text { desinflación (\%) }\end{array}$ & $\begin{array}{l}\text { coeficiente } \\
\text { de sacrificio }\end{array}$ & $\begin{array}{l}\text { Régimen } \\
\text { Cambiario }\end{array}$ \\
\hline Alemania & 1973-1 & $1977-3$ & 7.10 & 2.90 & 4.21 & 3.64 & 18 & 0.23 & 1.17 & flotación \\
\hline Alemania & $1981-1$ & $1986-3$ & 6.06 & -0.02 & 6.08 & 0.97 & 22 & 0.28 & 1.53 & flotación \\
\hline Alemania & $1992-2$ & $1995-4$ & 5.13 & 1.39 & 3.74 & 1.55 & 14 & 0.27 & 0.75 & flotación \\
\hline Argentina * & $1972-2$ & $1973-3$ & 62.69 & 44.25 & 18.45 & 206.10 & 5 & 3.69 & 0.13 & fijo \\
\hline Argentina * & $1976-2$ & $1980-4$ & 430.03 & 106.26 & 323.77 & 193.56 & 18 & 17.99 & -0.07 & flexible \\
\hline Argentina * & $1984-3$ & $1986-3$ & 761.48 & 114.79 & 646.70 & 299.64 & 4 & 161.67 & 0.01 & flexible \\
\hline Argentina & $1989-2$ & $1996-4$ & 27781.53 & 0.27 & 27781.27 & 0.81 & 30 & 926.04 & N.D. & fijo \\
\hline Australia & $1974-2$ & $1978-1$ & 15.50 & 8.35 & 7.15 & 9.63 & 15 & 0.48 & 0.68 & flexible \\
\hline Australia & $1982-1$ & $1984-1$ & 10.91 & 5.66 & 5.25 & 6.82 & 8 & 0.66 & 1.45 & flexible \\
\hline Austria & $1974-3$ & $1978-2$ & 9.02 & 3.56 & 5.46 & 5.08 & 15 & 0.36 & 0.87 & fijo \\
\hline Austria & $1981-1$ & $1987-2$ & 6.91 & 1.29 & 5.61 & 2.64 & 25 & 0.22 & 1.63 & fijo \\
\hline Canadá & $1974-3$ & $1977-1$ & 11.06 & 7.52 & 3.54 & 9.18 & 10 & 0.35 & 0.41 & flexible \\
\hline Canadá & $1981-2$ & $1985-2$ & 11.99 & 3.89 & 8.11 & 4.32 & 16 & 0.51 & 1.87 & flexible \\
\hline Canadá & $1990-1$ & $1993-4$ & 5.85 & 1.00 & 4.85 & 1.12 & 15 & 0.32 & 2.63 & flotación \\
\hline Canadá & $1996-1$ & $1997-3$ & 2.05 & 1.21 & 0.84 & 0.84 & 6 & 0.14 & 0.76 & flotación \\
\hline Corea & $1974-4$ & $1976-4$ & 26.24 & 10.80 & 15.44 & 14.23 & 8 & 1.93 & 0.35 & fijo \\
\hline Corea & $1980-2$ & $1984-2$ & 25.90 & 2.11 & 23.79 & 2.58 & 16 & 1.49 & 0.78 & flexible \\
\hline Corea & $1991-1$ & $1995-4$ & 9.02 & 4.17 & 4.85 & 7.04 & 19 & 0.26 & 0.77 & flexible \\
\hline Chile & $1974-3$ & $1981-3$ & 668.10 & 15.20 & 652.90 & 20.91 & 28 & 23.32 & N.D. & flexible \\
\hline Dinamarca & $1973-4$ & $1976-1$ & 13.25 & 8.45 & 4.80 & 11.35 & 9 & 0.53 & N.D. & fijo \\
\hline Dinamarca & $1980-2$ & $1986-3$ & 12.83 & 3.60 & 9.23 & 4.23 & 25 & 0.37 & N.D. & fijo \\
\hline Dinamarca & $1987-2$ & $1993-3$ & 5.04 & 1.47 & 3.58 & 2.02 & 25 & 0.14 & 4.40 & fijo \\
\hline Ecuador & $1974-2$ & $1976-2$ & 21.38 & 10.59 & 10.78 & 13.25 & 8 & 1.35 & N.D. & fijo \\
\hline Ecuador * & $1977-3$ & $1978-4$ & 13.25 & 10.27 & 2.98 & 13.01 & 5 & 0.60 & N.D. & fijo \\
\hline Ecuador & $1989-2$ & $1990-3$ & 69.69 & 47.12 & 22.57 & 55.22 & 5 & 4.51 & N.D. & flexible \\
\hline Ecuador & $1991-4$ & $1995-3$ & 55.22 & 22.78 & 32.44 & 27.67 & 15 & 2.16 & N.D. & flexible \\
\hline España & $1977-2$ & $1987-2$ & 22.74 & 4.84 & 17.91 & 6.08 & 40 & 0.45 & 2.45 & flexible \\
\hline España & $1989-3$ & $1997-3$ & 7.12 & 1.89 & 5.23 & 1.99 & 32 & 0.16 & 0.65 & fijo \\
\hline Estados Unidos * & $1969-4$ & $1971-4$ & 5.64 & 3.68 & 1.96 & 6.56 & 8 & 0.25 & 2.59 & fijo \\
\hline Estados Unidos * & $1974-2$ & $1976-4$ & 10.03 & 5.91 & 4.11 & 8.09 & 10 & 0.41 & 2.13 & flotación \\
\hline Estados Unidos & $1980-1$ & $1985-4$ & 12.48 & 2.49 & 9.99 & 2.85 & 23 & 0.43 & 2.05 & flotación \\
\hline Estados Unidos & $1989-4$ & $1994-3$ & 5.28 & 2.63 & 2.65 & 2.81 & 19 & 0.14 & 3.68 & flotación \\
\hline Filipinas & $1974-1$ & $1975-4$ & 26.90 & 6.75 & 20.15 & 10.14 & 7 & 2.88 & N.D. & flotación \\
\hline Filipinas & $1984-1$ & $1986-2$ & 37.87 & 1.98 & 35.89 & 6.19 & 9 & 3.99 & 0.35 & flexible \\
\hline Filipinas & $1990-1$ & $1995-4$ & 17.26 & 7.33 & 9.93 & 6.03 & 27 & 0.37 & 3.21 & flotación \\
\hline Finlandia & $1975-1$ & $1978-4$ & 17.66 & 7.27 & 10.39 & 10.85 & 15 & 0.69 & 1.40 & flexible \\
\hline Finlandia & $1981-1$ & $1986-4$ & 12.03 & 3.32 & 8.71 & 5.08 & 23 & 0.38 & 0.50 & flexible \\
\hline Finlandia & $1989-1$ & $1993-4$ & 6.66 & 1.71 & 4.95 & 1.05 & 27 & 0.18 & 6.09 & flexible \\
\hline Holanda & $1975-2$ & $1978-3$ & 10.23 & 3.88 & 6.35 & 5.43 & 13 & 0.49 & N.D. & fijo \\
\hline Holanda & $1980-4$ & $1987-1$ & 6.93 & -0.55 & 7.47 & 0.94 & 25 & 0.30 & 2.15 & fijo \\
\hline Holanda & $1991-2$ & $1997-3$ & 3.29 & 1.91 & 1.37 & 1.83 & 25 & 0.05 & 8.94 & fijo \\
\hline Israel & $1989-4$ & 1993-1 & 19.65 & 9.97 & 9.68 & 11.13 & 13 & 0.74 & -0.13 & flexible \\
\hline Italia & $1980-4$ & $1987-3$ & 20.44 & 4.65 & 15.79 & 5.83 & 27 & 0.58 & 1.25 & fijo \\
\hline Italia & $1989-4$ & $1993-3$ & 6.62 & 4.08 & 2.54 & 4.70 & 15 & 0.17 & -1.28 & fijo \\
\hline Italia & $1995-1$ & $1996-3$ & 4.72 & 2.86 & $\begin{array}{l}2.84 \\
1.86\end{array}$ & 1.97 & 6 & 0.31 & -0.54 & fijo \\
\hline Japón & $1974-1$ & $1978-3$ & 18.60 & 3.76 & 14.84 & 5.83 & 18 & 0.82 & -0.41 & flotación \\
\hline Japón & $1980-2$ & $1987-1$ & 6.92 & 0.02 & 6.90 & 1.93 & 27 & 0.26 & 0.84 & flotación \\
\hline Japón & $1990-2$ & $1996-1$ & 3.74 & -0.11 & 3.85 & 1.38 & 23 & 0.17 & -0.89 & flotación \\
\hline México * & $1974-2$ & $1975-3$ & 20.02 & 14.28 & 5.74 & 22.69 & 5 & 1.15 & N.D. & fijo \\
\hline México * & 1983-2 & $1984-3$ & 90.43 & 60.56 & 29.87 & 78.67 & 5 & 5.97 & 0.07 & flexible \\
\hline México * & $1987-1$ & $1993-4$ & 142.30 & 8.11 & 134.19 & 30.26 & 27 & 4.97 & 0.05 & flexible \\
\hline México & $1996-1$ & $1997-4$ & 38.56 & 17.55 & 21.01 & 16.46 & 7 & 3.00 & N.D. & flotación \\
\hline Noruega * & $1975-1$ & $1978-4$ & 10.79 & 6.04 & 4.76 & 10.15 & 15 & 0.32 & -0.91 & fijo \\
\hline Noruega & $1981-1$ & $1984-4$ & 13.49 & 5.78 & 7.71 & 7.80 & 15 & 0.51 & 1.62 & flexible \\
\hline Noruega & $1987-1$ & $1995-1$ & 8.40 & 1.64 & 6.76 & 1.98 & 32 & 0.21 & 6.32 & flexible \\
\hline Nueva Zelandia * & $1976-2$ & $1978-1$ & 15.98 & 12.45 & 3.53 & 14.67 & 7 & 0.50 & N.D. & flexible \\
\hline Nueva Zelandia * & $1980-2$ & $1983-4$ & 16.73 & 7.06 & 9.67 & 12.14 & 14 & 0.69 & N.D. & flexible \\
\hline Nueva Zelandia & $1985-4$ & $1992-2$ & 16.68 & 1.05 & 15.62 & 1.61 & 26 & 0.60 & -0.23 & flotación \\
\hline Portugal * & $1976-2$ & $1980-3$ & 24.37 & 18.62 & 5.75 & 21.05 & 17 & 0.34 & N.D. & flexible \\
\hline Portugal & $1984-1$ & $1987-2$ & 29.04 & 8.91 & 20.13 & 10.88 & 13 & 1.55 & 0.52 & flexible \\
\hline Portugal & $1990-1$ & $1997-3$ & 13.27 & 2.31 & 10.96 & 3.11 & 30 & 0.37 & 0.25 & flexible \\
\hline Reino Unido & $1975-1$ & $1978-2$ & 21.29 & 10.28 & 11.01 & 15.39 & 13 & 0.85 & 0.69 & fijo \\
\hline Reino Unido & $1980-2$ & $1983-3$ & 16.65 & 4.38 & 12.27 & 5.16 & 13 & 0.94 & 0.93 & fijo \\
\hline Reino Unido & $1984-2$ & $1986-3$ & 6.36 & 3.21 & 3.15 & 5.34 & 9 & 0.35 & 0.93 & fijo \\
\hline Reino Unido & $1989-2$ & 1993-3 & 9.13 & 1.76 & 7.37 & 2.76 & 17 & 0.43 & 1.12 & fijo \\
\hline Suecia * & $1977-1$ & $1978-4$ & 11.53 & 8.48 & 3.06 & 12.56 & 7 & 0.44 & 1.47 & flexible \\
\hline Suecia & $1980-3$ & $1986-3$ & 12.84 & 4.07 & 8.77 & 5.40 & 24 & 0.37 & 1.61 & tlexible \\
\hline Suecia & $1990-1$ & 1993-1 & 10.02 & 2.95 & 7.07 & 2.43 & 12 & 0.59 & -0.21 & flexible \\
\hline Suecia & $1993-4$ & $1997-3$ & 3.49 & -0.07 & 3.56 & -0.62 & 11 & 0.32 & -1.04 & flotación \\
\hline Suiza & $1973-4$ & $1977-4$ & 9.87 & 1.04 & 8.83 & 2.88 & 16 & 0.55 & 0.92 & tijo \\
\hline Suiza & $1981-3$ & $1983-4$ & 6.25 & 2.52 & 3.73 & 2.87 & 9 & 0.41 & 1.07 & fijo \\
\hline Suiza & $1990-4$ & $1997-3$ & 5.79 & 0.26 & 5.53 & 0.06 & 27 & 0.20 & 1.42 & fijo \\
\hline \multirow[t]{2}{*}{ Promedio } & \multicolumn{2}{|c|}{$\begin{array}{l}\text { Solamente Coeficientes } \\
\text { de Sacrificio positivos }\end{array}$} & 39.91 & 8.52 & 31.39 & 17.57 & 17.90 & 4.73 & 1.58 & \\
\hline & \multicolumn{2}{|c|}{ Todos los episodios } & 403.63 & 11.68 & 391.95 & 20.81 & 16.51 & 15.76 & 1.15 & \\
\hline
\end{tabular}

* Periodo de desinflación no sostenible, de acuerdo a los criterios establecidos en las páginas 14 a 15. 


\section{Cuadro A-2}

Periodos desinflacionarios con una inflación inicial menor a 10\%

\begin{tabular}{|c|c|c|c|c|c|c|c|c|c|c|c|}
\hline País & Inicio & Fin & $\pi$ incial (\%) & $\pi$ tinal (\%) & reduccion en $\pi$ (\%) & $\begin{array}{l}\pi \text { del fin a } 2 \text { años } \\
\text { después de desinf. }\end{array}$ & $\begin{array}{l}\text { duración } \\
\text { (periodos) }\end{array}$ & $\begin{array}{c}\text { velocidad de } \\
\text { desinflación (\%) }\end{array}$ & $\begin{array}{l}\text { coeficiente de } \\
\text { sacrifico }\end{array}$ & $\begin{array}{l}\text { Dep(+) TC real } \\
\text { durante la des. }\end{array}$ & $\begin{array}{l}\text { Dep(+) TC real } \\
2 \text { años después }\end{array}$ \\
\hline Alemania & 1973-1 & $1977-3$ & 7.10 & 2.90 & 4.21 & 3.64 & 18 & 0.23 & 1.17 & N.D. & N.D. \\
\hline Alemania & $1981-1$ & $1986-3$ & 6.06 & -0.02 & 6.08 & 0.97 & 22 & 0.28 & 1.53 & -0.5 & 1.4 \\
\hline Alemania & $1992-2$ & $1995-4$ & 5.13 & 1.39 & 3.74 & 1.55 & 14 & 0.27 & 0.75 & -10.7 & 9.2 \\
\hline Australia & $1986-2$ & 1993-1 & 8.99 & 1.16 & 7.83 & 2.94 & 27 & 0.29 & -0.42 & 6.7 & -0.1 \\
\hline Austria & $1974-3$ & $1978-2$ & 9.02 & 3.56 & 5.46 & 5.08 & 15 & 0.36 & 0.87 & N.D. & N.D. \\
\hline Austria & $1981-1$ & $1987-2$ & 6.91 & 1.29 & 5.61 & 2.64 & 25 & 0.22 & 1.63 & -8.4 & 2.3 \\
\hline Canadá & $1990-1$ & $1993-4$ & 5.85 & 1.00 & 4.85 & 1.12 & 15 & 0.32 & 2.63 & 16.2 & 9.0 \\
\hline Canadá & $1996-1$ & $1997-3$ & 2.05 & 1.21 & 0.84 & 0.84 & 6 & 0.14 & 0.76 & -2.2 & 12.01 \\
\hline Corea & $1991-1$ & $1995-4$ & 9.02 & 4.17 & 4.85 & 7.04 & 19 & 0.26 & 0.77 & -5.36 & 41.60 \\
\hline Dinamarca & $1987-2$ & $1993-3$ & 5.04 & 1.47 & 3.58 & 2.02 & 25 & 0.14 & 4.40 & 3.7 & -6.7 \\
\hline España & $1989-3$ & $1997-3$ & 7.12 & 1.89 & 5.23 & 1.99 & 32 & 0.16 & 0.65 & 13.1 & -2.27 \\
\hline Estados Unidos * & $1969-4$ & $1971-4$ & 5.64 & 3.68 & 1.96 & 6.56 & 8 & 0.25 & 2.59 & N.D. & N.D. \\
\hline Estados Unidos & $1989-4$ & $1994-3$ & 5.28 & 2.63 & 2.65 & 2.81 & 19 & 0.14 & 3.68 & 7.1 & -2.5 \\
\hline Finlandia & $1989-1$ & $1993-4$ & 6.66 & 1.71 & 4.95 & 1.05 & 27 & 0.18 & 6.09 & 34.0 & -13.8 \\
\hline Holanda & $1980-4$ & $1987-1$ & 6.93 & -0.55 & 7.47 & 0.94 & 25 & 0.30 & 2.15 & 0.9 & 7.4 \\
\hline Holanda & $1991-2$ & $1997-3$ & 3.29 & 1.91 & 1.37 & 1.83 & 25 & 0.05 & 8.94 & -1.2 & -3.59 \\
\hline Italia & $1989-4$ & $1993-3$ & 6.62 & 4.08 & 2.54 & 4.70 & 15 & 0.17 & -1.28 & 15.3 & 9.6 \\
\hline Italia & $1995-1$ & $1996-3$ & 4.72 & 2.86 & 1.86 & 1.97 & 6 & 0.31 & -0.54 & -11.1 & -0.7 \\
\hline Japón & $1980-2$ & $1987-1$ & 6.92 & 0.02 & 6.90 & 1.93 & 27 & 0.26 & 0.84 & -32.9 & -7.0 \\
\hline Japón & $1990-2$ & 1996-1 & 3.74 & -0.11 & 3.85 & 1.38 & 23 & 0.17 & -0.89 & -21.9 & 5.8 \\
\hline Noruega & $1987-1$ & $1995-1$ & 8.40 & 1.64 & 6.76 & 1.98 & 32 & 0.21 & 6.32 & 3.5 & -4.9 \\
\hline Reino Unido & $1984-2$ & $1986-3$ & 6.36 & 3.21 & 3.15 & 5.34 & 9 & 0.35 & 0.93 & 7.4 & -8.4 \\
\hline Reino Unido & $1989-2$ & $1993-3$ & 9.13 & 1.76 & 7.37 & 2.76 & 17 & 0.43 & 1.12 & 9.2 & 5.3 \\
\hline Suecia & $1993-4$ & $1997-3$ & 3.49 & -0.07 & 3.56 & -0.62 & 11 & 0.32 & -1.04 & -5.1 & 8.96 \\
\hline Suiza & $1973-4$ & $1977-4$ & 9.87 & 1.04 & 8.83 & 2.88 & 16 & 0.55 & 0.92 & N.D. & N.D. \\
\hline Suiza & $1981-3$ & $1983-4$ & 6.25 & 2.52 & 3.73 & 2.87 & 9 & 0.41 & 1.07 & -7.7 & 2.8 \\
\hline Suiza & $1990-4$ & $1997-3$ & 5.79 & 0.26 & 5.53 & 0.06 & 27 & 0.20 & 1.42 & 2.8 & -2.77 \\
\hline Promedio & \multicolumn{2}{|c|}{$\begin{array}{l}\text { Solamente Coeficientes } \\
\text { de Sacrificio positivos ** }\end{array}$} & 6.23 & 1.53 & 4.70 & 2.45 & 20.83 & 0.24 & 2.54 & 1.61 & 2.16 \\
\hline & \multicolumn{2}{|c|}{ Todas las observaciones } & 6.35 & 1.73 & 4.62 & 3.32 & 19.04 & 0.26 & 1.74 & 0.56 & 2.72 \\
\hline
\end{tabular}

* Periodo de desinflación no sostenible, de acuerdo a los criterios establecidos en las páginas 14 a 15.

** Se consideran únicamente los periodos desinflacionarios sostenibles para los que haya datos de coeficiente de sacrificio y tipo de cambio real 


\section{Cuadro A-3}

Periodos desinflacionarios con una inflación inicial entre 10\% y 20\%

\begin{tabular}{|c|c|c|c|c|c|c|c|c|c|c|c|}
\hline País & Inicio & Fin & $\pi$ mulas $(7)$ & ル ImIa1 (w) & 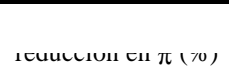 & $\begin{array}{l}\pi \text { del tın a } 2 \text { años } \\
\text { después de desinf. }\end{array}$ & $\begin{array}{l}\text { duración } \\
\text { (periodos) }\end{array}$ & $\begin{array}{c}\text { velocidad de } \\
\text { desinflación (\%) }\end{array}$ & $\begin{array}{l}\text { coeficiente de } \\
\text { sacrifico }\end{array}$ & $\begin{array}{l}\text { Dep(+) TC real } \\
\text { durante la des. }\end{array}$ & $\begin{array}{l}\text { Dep }(+) \text { TC re: } \\
2 \text { años despué }\end{array}$ \\
\hline Australia & $1974-2$ & $1978-1$ & 15.50 & 8.35 & 7.15 & 9.63 & 15 & 0.48 & 0.68 & N.D. & N.D. \\
\hline Australia & $1982-1$ & $1984-1$ & 10.91 & 5.66 & 5.25 & 6.82 & 8 & 0.66 & 1.45 & -2.5 & 31.3 \\
\hline Canadá & $1974-3$ & $1977-1$ & 11.06 & 7.52 & 3.54 & 9.18 & 10 & 0.35 & 0.41 & N.D. & N.D. \\
\hline Canadá & $1981-2$ & $1985-2$ & 11.99 & 3.89 & 8.11 & 4.32 & 16 & 0.51 & 1.87 & -6.9 & 12.6 \\
\hline Dinamarca & 1973-4 & $1976-1$ & 13.25 & 8.45 & 4.80 & 11.35 & 9 & 0.53 & N.D. & N.D. & N.D. \\
\hline Dinamarca & $1980-2$ & $1986-3$ & 12.83 & 3.60 & 9.23 & 4.23 & 25 & 0.37 & N.D. & -0.4 & -2.3 \\
\hline Ecuador * & $1977-3$ & $1978-4$ & 13.25 & 10.27 & 2.98 & 13.01 & 5 & 0.60 & N.D. & N.D. & N.D. \\
\hline Estados Unidos * & $1974-2$ & $1976-4$ & 10.03 & 5.91 & 4.11 & 8.09 & 10 & 0.41 & 2.13 & N.D. & N.D. \\
\hline Estados Unidos & $1980-1$ & $1985-4$ & 12.48 & 2.49 & 9.99 & 2.85 & 23 & 0.43 & 2.05 & -23.0 & 28.1 \\
\hline Filipinas & $1990-1$ & $1995-4$ & 17.26 & 7.33 & 9.93 & 6.03 & 27 & 0.37 & 3.21 & -15.5 & 12.2 \\
\hline Finlandia & $1975-1$ & $1978-4$ & 17.66 & 7.27 & 10.39 & 10.85 & 15 & 0.69 & 1.40 & N.D. & N.D. \\
\hline Finlandia & $1981-1$ & $1986-4$ & 12.03 & 3.32 & 8.71 & 5.08 & 23 & 0.38 & 0.50 & -5.5 & -5.5 \\
\hline Holanda & $1975-2$ & $1978-3$ & 10.23 & 3.88 & 6.35 & 5.43 & 13 & 0.49 & N.D. & N.D. & N.D. \\
\hline Israel & $1989-4$ & $1993-1$ & 19.65 & 9.97 & 9.68 & 11.13 & 13 & 0.74 & -0.13 & 1.67 & -9.00 \\
\hline Japón & $1974-1$ & 1978-3 & 18.60 & 3.76 & 14.84 & 5.83 & 18 & 0.82 & -0.41 & N.D. & N.D. \\
\hline Noruega * & $1975-1$ & $1978-4$ & 10.79 & 6.04 & 4.76 & 10.15 & 15 & 0.32 & -0.91 & N.D. & N.D. \\
\hline Noruega & $1981-1$ & $1984-4$ & 13.49 & 5.78 & 7.71 & 7.80 & 15 & 0.51 & 1.62 & -1.7 & 2.6 \\
\hline Nueva Zelandia * & $1976-2$ & $1978-1$ & 15.98 & 12.45 & 3.53 & 14.67 & 7 & 0.50 & N.D. & N.D. & N.D. \\
\hline Nueva Zelandia * & $1980-2$ & $1983-4$ & 16.73 & 7.06 & 9.67 & 12.14 & 14 & 0.69 & N.D. & -0.4 & -3.2 \\
\hline Nueva Zelandia & $1985-4$ & $1992-2$ & 16.68 & 1.05 & 15.62 & 1.61 & 26 & 0.60 & -0.23 & 9.1 & -7.2 \\
\hline Portugal & $1990-1$ & $1997-3$ & 13.27 & 2.31 & 10.96 & 3.11 & 30 & 0.37 & 0.25 & -12.7 & -3.46 \\
\hline Reino Unido & $1980-2$ & $1983-3$ & 16.65 & 4.38 & 12.27 & 5.16 & 13 & 0.94 & 0.93 & 5.3 & -0.1 \\
\hline Suecia * & 1977-1 & $1978-4$ & 11.53 & 8.48 & 3.06 & 12.56 & 7 & 0.44 & 1.47 & N.D. & N.D. \\
\hline Suecia & 1980-3 & $1986-3$ & 12.84 & 4.07 & 8.77 & 5.40 & 24 & 0.37 & 1.61 & 15.5 & -3.2 \\
\hline Suecia & $1990-1$ & $1993-1$ & 10.02 & 2.95 & 7.07 & 2.43 & 12 & 0.59 & -0.21 & 11.2 & 6.6 \\
\hline \multirow[t]{2}{*}{ Promedio } & \multicolumn{2}{|c|}{$\begin{array}{l}\text { Solamente Coeficientes } \\
\text { de Sacrificio positivos ** }\end{array}$} & 13.44 & 4.36 & 9.08 & 6.10 & 19.89 & 0.50 & 1.50 & -5.22 & 8.29 \\
\hline & \multicolumn{2}{|c|}{ Todas las observaciones } & 13.79 & 5.85 & 7.94 & 8.49 & 15.72 & 0.53 & 0.93 & -1.85 & 4.25 \\
\hline
\end{tabular}

* Periodo de desinflación no sostenible, de acuerdo a los criterios establecidos en las páginas 14 a 15.

** Se consideran únicamente los periodos desinflacionarios sostenibles para los que haya datos de coeficiente de sacrificio y tipo de cambio real 


\section{Cuadro A-4}

Periodos desinflacionarios con una inflación inicial entre 20\% y 40\%

\begin{tabular}{|c|c|c|c|c|c|c|c|c|c|c|c|}
\hline País & Inicio & Fin & $\pi$ musar $(w)$ & Mnam (n) & 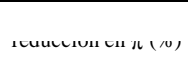 & $\begin{array}{l}\pi \text { ael Inn a } \angle \text { anos } \\
\text { después de desinf. }\end{array}$ & $\begin{array}{l}\text { duración } \\
\text { (periodos) }\end{array}$ & $\begin{array}{c}\text { velocidad de } \\
\text { desinflación (\%) }\end{array}$ & $\begin{array}{l}\text { coeficiente de } \\
\text { sacrifico }\end{array}$ & $\begin{array}{l}\text { Dep(+) TC real } \\
\text { durante la des. }\end{array}$ & $\begin{array}{l}\text { Dep(+) TC real } \\
2 \text { años después }\end{array}$ \\
\hline Corea & $1974-4$ & $1976-4$ & 26.24 & 10.80 & 15.44 & 14.23 & 8 & 1.93 & 0.35 & -7.75 & -9.97 \\
\hline Corea & $1980-2$ & $1984-2$ & 25.90 & 2.11 & 23.79 & 2.58 & 16 & 1.49 & 0.78 & 20.46 & 10.97 \\
\hline Chile * & $1983-4$ & $1988-3$ & 27.62 & 16.20 & 11.42 & 24.56 & 19 & 0.60 & 1.25 & 68.3 & 1.7 \\
\hline Chile & $1989-4$ & $1997-3$ & 24.56 & 5.34 & 19.23 & 5.09 & 31 & 0.62 & 0.39 & -28.5 & 7.36 \\
\hline Ecuador & $19 / 4-2$ & $19 / 6-2$ & 21.38 & 10.59 & 10.18 & 13.25 & 8 & 1.35 & N.U. & N.U. & N.U. \\
\hline España & $19 / 1-2$ & $198 /-2$ & 22.14 & 4.84 & $1 / .91$ & 6.08 & 40 & $0.4 b$ & 2.45 & N.U. & -10.5 \\
\hline Filipinas & $1974-1$ & $1975-4$ & 26.90 & 6.75 & 20.15 & 10.14 & 7 & 2.88 & N.D. & N.D. & N.D. \\
\hline Filipinas & 1984-1 & $1986-2$ & 37.87 & 1.98 & 35.89 & 6.19 & 9 & 3.99 & 0.35 & 15.9 & 12.0 \\
\hline Italia & $1980-4$ & $1987-3$ & 20.44 & 4.65 & 15.79 & 5.83 & 27 & 0.58 & 1.25 & -12.2 & -2.8 \\
\hline México * & $1974-2$ & $1975-3$ & 20.02 & 14.28 & 5.74 & 22.69 & 5 & 1.15 & N.D. & -5.8 & 41.1 \\
\hline Portugal $*$ & $1976-2$ & $1980-3$ & 24.37 & 18.62 & 5.75 & 21.05 & 17 & 0.34 & N.D. & N.D. & -0.5 \\
\hline Portugal & 1984-1 & $1987-2$ & 29.04 & 8.91 & 20.13 & 10.88 & 13 & 1.55 & 0.52 & -1.3 & -4.1 \\
\hline Reino Unido & $19 / 5-1$ & $1 y / 8-2$ & 21.29 & 10.28 & 11.01 & 15.39 & 13 & 0.85 & 0.69 & N.U. & N.U. \\
\hline \multirow[t]{2}{*}{ Promedio } & \multicolumn{2}{|c|}{$\begin{array}{l}\text { Solamente Coeficientes } \\
\text { de Sacrificio positivos ** }\end{array}$} & 27.34 & 5.63 & 21.71 & 9.53 & 17.33 & 1.69 & 0.61 & -2.22 & 2.25 \\
\hline & \multicolumn{2}{|c|}{ Todas las observaciones } & 26.21 & 9.49 & 16.72 & 13.62 & 15.71 & 1.48 & 0.89 & 2.71 & 4.97 \\
\hline
\end{tabular}

\section{Cuadro A-5}

Periodos desinflacionarios con una inflación inicial mayor a 40\%

\begin{tabular}{|c|c|c|c|c|c|c|c|c|c|c|c|}
\hline País & Inicio & Fin & ル mula, (w) & $\pi$ tнан $(10)$ & 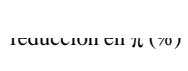 & $\begin{array}{l}\pi \text { del tın a } \angle \text { anos } \\
\text { después de desinf. }\end{array}$ & $\begin{array}{l}\text { duración } \\
\text { (periodos) }\end{array}$ & $\begin{array}{c}\text { velocidad de } \\
\text { desinflación (\%) }\end{array}$ & $\begin{array}{l}\text { coeficiente de } \\
\text { sacrifico }\end{array}$ & $\begin{array}{l}\text { Dep(+) TC real } \\
\text { durante la des. }\end{array}$ & $\begin{array}{l}\text { Dep(+) TC real } \\
2 \text { años después }\end{array}$ \\
\hline Argentina * & $1972-2$ & 1973-3 & 62.69 & 44.25 & 18.45 & 206.10 & 5 & 3.69 & 0.13 & -38.63 & 156.61 \\
\hline Argentina * & $1976-2$ & $1980-4$ & 430.03 & 106.26 & 323.77 & 193.56 & 18 & 17.99 & -0.07 & -58.91 & 263.40 \\
\hline Argentina * & 1984-3 & $1986-3$ & 761.48 & 114.79 & 646.70 & 299.64 & 4 & 161.67 & 0.01 & 3.17 & 5.24 \\
\hline Chile & $1974-3$ & $1981-3$ & 668.10 & 15.20 & 652.90 & 20.91 & 28 & 23.32 & N.D. & N.D. & 37.4 \\
\hline Ecuador & $1989-2$ & $19 y 0-3$ & $69.6 y$ & $4 / .12$ & $22.5 /$ & ५५.22 & $b$ & 4.51 & N.U. & 15.3 & -1.0 \\
\hline Ecuador & $1991-4$ & $1995-3$ & b̧.2'2 & 22.18 & 32.44 & 21.61 & 15 & 2.16 & N.U. & $-1 / .9$ & -8.2 \\
\hline Israel * & 1974-1 & $1976-2$ & 40.18 & 29.62 & 10.55 & 41.65 & 9 & 1.17 & -0.30 & 10.96 & 24.74 \\
\hline Israel * & $1980-4$ & $198<-1$ & 126.21 & 118.21 & 1.94 & 219.31 & b & $1.5 y$ & $-0.1 y$ & $16.1 y$ & 1.06 \\
\hline Israel & 1984-3 & $1987-1$ & 372.44 & 17.90 & 354.54 & 18.16 & 10 & 35.45 & 0.01 & -14.58 & -11.35 \\
\hline México * & $1983-2$ & 1984-3 & 90.43 & 60.56 & 29.87 & 78.67 & 5 & 5.97 & 0.07 & -19.4 & 62.0 \\
\hline México * & 1987-1 & 1993-4 & 142.30 & 8.11 & 134.19 & 30.26 & 27 & 4.97 & 0.05 & -48.6 & 67.0 \\
\hline \multirow[t]{2}{*}{ Promedio } & \multicolumn{2}{|c|}{$\begin{array}{l}\text { Solamente Coeficientes } \\
\text { de Sacrificio positivos ** }\end{array}$} & 372.44 & 17.90 & 354.54 & 18.15 & 10.00 & 35.45 & 0.01 & -14.58 & -11.35 \\
\hline & \multicolumn{2}{|c|}{ Todas las observaciones } & 2550.03 & 48.16 & 2501.21 & $22 / \zeta . / 3$ & 13.42 & yy.us & -0.04 & -20.92 & 49.96 \\
\hline
\end{tabular}

* Periodo de desinflación no sostenible, de acuerdo a los criterios establecidos en las páginas 14 a 15 .

** Se consideran únicamente los periodos desinflacionarios sostenibles para los que haya datos de coeficiente de sacrificio y tipo de cambio real 